The compression chord capacity model for the shear design and assessment of reinforced

and prestressed concrete beams

\title{
Antoni Cladera
}

Associate professor

University of Balearic Islands

Department of Physics

Ctra. Valldemossa, km 7.5, Palma (Balearic Islands), Spain

Phone number: +34971171378

Fax number: +34971 173426

E-mail:antoni.cladera@uib.es

\section{Antonio Marí}

Professor

Universitat Politècnica de Catalunya

Department of Civil and Environmental Engineering

Jordi Girona 1-3, C-1 201, 08034 Barcelona, Spain

\section{Jesus Bairán}

Associate professor

Universitat Politècnica de Catalunya

Department of Civil and Environmental Engineering

Jordi Girona 1-3, C-1 201, 08034 Barcelona, Spain

\section{Carlos Ribas}

Associate professor

University of Balearic Islands

Department of Physics

Ctra. Valldemossa, km 7.5, Palma (Balearic Islands), Spain

\section{Eva Oller}

Assistant professor

Universitat Politècnica de Catalunya

Department of Civil and Environmental Engineering

Jordi Girona 1-3, C-1 201, 08034 Barcelona, Spain

\section{Noemí Duarte}

Researcher

Universitat Politècnica de Catalunya

Department of Civil and Environmental Engineering

Jordi Girona 1-3, C-1 201, 08034 Barcelona, Spain

Running head: Shear design and assessment of RC and PC beams 


\begin{abstract}
A simplified mechanical model for the shear strength prediction of reinforced and prestressed concrete members with and without transverse reinforcement, with I, T or rectangular cross section is presented. The model, derived after further simplifications of a previous one developed by the authors, incorporates in a compact formulation, the contributions of the concrete compression chord, the cracked web, the dowel action and the shear reinforcement. The mechanical character of the model provides valuable information about the physics of the problem and incorporates the most relevant parameters governing the shear strength of structural concrete members. The predictions of the model fit very well the experimental results collected in the ACI-DAfStb databases of shear tests on slender reinforced and prestressed concrete beams with and without stirrups. Due to this fact and the simplicity of the derived equations it may become a very useful tool for structural design and assessment in engineering practice.
\end{abstract}

Keywords: Shear strength, mechanical model, structural code, reinforced concrete, prestressed concrete; T-beam; stirrups, shear-flexure interaction, design, assessment.

\title{
1. Introduction
}

As Golder [1] brilliantly pointed out in the first issue of Géotechnique, in June 1948, "there are two approaches to a natural problem. They are the approach of the pure scientist and that of the engineer. The pure scientist is interested only in the truth. For him there is only one answerthe right one - no matter how long it takes to get it. For the engineer, on the other hand, there are many possible answers, all of which are compromises between the truth and time, for the engineer must have an answer now; his answer must be sufficient for a given purpose, even if not true. For this reason an engineer must make assumptions - assumptions which in some cases he knows to be not strictly correct - but which will enable him to arrive at an answer which is sufficiently true for the immediate purpose. Mistakes are not made when an engineer makes his 
assumption. Mistakes are made when other engineers forget the assumptions which have been made $[\ldots]$ ". This thought, which was dedicated to Coulomb and the earth pressure, is completely valid for the modelling of the "riddle of shear failure" [2]. For example, Mörsch recognised that his pioneer model was a simplification, since some of the transverse force could be resisted by inclination of the flexural compression chord, and, the ribs of concrete between flexural cracks would bend and produce dowel forces in the main steel [3].

It is essential, therefore, when dealing with models for a structural code, to know the purpose of that code. The purpose will fix the level of the simplifications that can be accepted. In general, most current structural codes, as EC2 [4] or ACI 318-11 [5], were conceived for the design of new structures. With this purpose in mind, very simple models are adequate, as the main objective it is not to predict the actual strength of a structure, but to design it in a safe way. However, the assessment of structures is a topic of increasing interest for everyday engineering. For this reason, the inclusion of the assessment in the purpose of a given Structural Code makes it necessary to rethink the models included and the simplifications carried out. Moreover, the construction sector is everyday more open to new materials and technologies. Therefore, a code should not be "a set of rules prepared by a few for the regulation of other engineers, but a synthesis of contemporary knowledge, practices and techniques" [6], based on mechanical models, to allow their natural extension to new applications that were probably not envisaged when the initial mechanical model was developed.

An incredible amount of research on shear strength of concrete members has been conducted since the mid-1950s [3], and even before. Thanks to this continuous research, that is impossible to summarize in a research paper, refined analytical and numerical models have been developed [7-15]. At the same time, simplified models for the shear strength of RC and PC members, based on sound theories, have also been presented [16-22]. As Regan pointed out [3], "for simpler models the problem is mostly that of the need to neglect secondary factors, while what is secondary in one case may be primary in another". Regan also concluded that significant improvements for design were very likely to be initiated by experimental observations [3]. 
This paper deals with the simplification of a multi-action mechanical model for the shear design and assessment of RC and PC beams previously developed by the authors which is valid for reinforced concrete and for prestressed concrete members with any degree of prestressing, with or without stirrups, for normal or high strength concrete, for T, I or rectangular sections [23-25]. The predictions of the original mechanical model were compared with four large database of tests results on RC and PC beams developed by ACI-DafStb [26-28], showing small bias and scatter, and it had also been extended to FRP RC beams [29, 30]. However, for design purposes, some simplifications are still necessary in order to make the mechanical model easier to use in daily engineering practice. In this paper, the assumptions made for the derivation of the original mechanical model, and for the further simplification to reach code-type expressions will be highlighted. The main focus of this paper is to allow practicing engineers to understand and use this model and to extend it to other cases.

\section{Theoretical background}

It is considered that the shear strength, $V_{u}$ in Eq. (1), is the sum of the shear resisted by concrete and by the transverse reinforcement $\left(V_{s}\right)$, and it must be lower than the shear force that produce failure in the concrete struts, $V_{u, \max }$ in Eq. (2). The concrete contribution is explicitly separated (see Eq. 1) into the shear resisted in the uncracked compression chord $\left(V_{c}\right)$, shear transferred across web cracks $\left(V_{w}\right)$ and the dowel action in the longitudinal reinforcement $\left(V_{l}\right)$. The importance of the different contributing actions is considered to be variable as cracks open and propagate.

$$
\begin{aligned}
& V_{u}=\left(V_{c}+V_{w}+V_{l}\right)+V_{s}=f_{c t m} \cdot b \cdot d \cdot\left(v_{c}+v_{w}+v_{l}\right)+v_{s} \cdot f_{c t m} \cdot b \cdot d \\
& V_{u, \max }=\alpha_{c w} b_{w} z v_{1} f_{c m} \frac{\cot \theta}{1+\cot ^{2} \theta}
\end{aligned}
$$

Lower case variables $v_{c}, v_{w}, v_{l}$ and $v_{s}$ are the dimensionless values of the shear transfer actions considered in the multi-action model or background mechanical model, whose expressions are given in Table 1 (Eqs. 3-6). The complete derivation of these equations may be 
found in $[23,25]$. The different parameters needed to compute Eq. (1) are also given in Table 1 (Eqs. 7-12) and in the notation. For the maximum shear strength due to the strut crushing, Eq. (2), this model adopts the formulation of the current EC-2, derived from plasticity models, but assuming that the angle of the compression strut is equal to the angle of the critical crack given by Eq. (12). Strut crushing is not a common failure mode, but it is possible in cases when larger contribution of $V_{s}$ exists, so the verification is introduced. As larger values of $V_{s}$ implies large amount of stirrups, usually this will occur with smear cracking in the web. Therefore, Eq. (2) represents here a check that another failure mode, strut crushing, prevents the occurrence of the compression chord failure. Note that these expressions do not include partial safety factors and that depend on mean values of the mechanical properties.

Table 1. Summary of dimensionless shear contributing components and factors considered in the mechanical model for members cracked in bending.

\begin{tabular}{ll}
\hline \multicolumn{1}{c}{ Contributing component } & \multicolumn{1}{c}{ Dimensionless expressions } \\
\hline Compression chord & $v_{c}=\zeta\left\{\left(0.88+\left(0.20+0.50 \frac{b}{b_{w}}\right) v_{s}\right) \frac{x}{d}+0.02\right\} \frac{b_{v, e f f}}{b} K_{p}$ \\
Cracked concrete web & $v_{w}=167 \frac{f_{c t m}}{E_{c m}} \frac{b_{w}}{b}\left(1+\frac{2 \cdot G_{f} \cdot E_{c m}}{f_{c t m}^{2} \cdot d_{0}}\right)$ \\
& if $v_{s}>0 \rightarrow v_{l}=0.23 \frac{\alpha_{e} \cdot \rho_{l}}{1-x / d}$ \\
Longitudinal reinforcement & if $v_{s}=0 \rightarrow v_{l}=0$ \\
Transversal reinforcement & $v_{s}=\left(d_{s}-x\right) \cot \theta \frac{A_{s w} \cdot f_{y w}}{s \cdot f_{c t m} \cdot b \cdot d} \approx \frac{0.85 d_{s} A_{s w} \cdot f_{y w}}{s \cdot f_{c t m} \cdot b \cdot d}$ \\
\hline \multicolumn{1}{c}{ Factors } & $x_{0}$ \\
\hline Neutral axis depth ratio for $\mathrm{RC}$ beam & $=\alpha_{e} \rho_{l}\left(-1+\sqrt{1+\frac{2}{\alpha_{e} \rho_{l}}}\right)$ \\
Neutral axis depth ratio for $\mathrm{PC}$ beam & $\frac{x}{d}=\frac{x_{0}}{d}+\left(\frac{h-x_{0}}{d}\right)\left(\frac{d}{h}\right) \frac{\sigma_{c p}}{\sigma_{c p}+f_{c t m}}$ \\
& if $x \leq h_{f} \rightarrow b_{v, e f f}=b_{v}=b_{w}+2 h_{f} \leq b$ \\
Effective width & if $x>h_{f} \rightarrow b_{v, e f f}=b_{v} \eta+b_{w}(1-\eta) ; \quad \eta=3\left(\frac{h_{f}}{x}\right)^{2}-2\left(\frac{h_{f}}{x}\right)^{3}$ \\
Strength factor related to $M_{c r}$ & $K_{p}=1+0.3 \frac{P \cos \alpha\left(x+d_{s}-d_{p}\right)}{f_{c t m} b d^{2}}$ \\
Size effect in compression chord & $\zeta=1.2-0.2 a \geq 0.65 \quad(a$ in meters $)$ \\
Critical crack inclination & $\cot \theta=\frac{0.85 d_{s}}{\left(d_{s}-x\right)} \leq 2.5$ \\
\hline
\end{tabular}




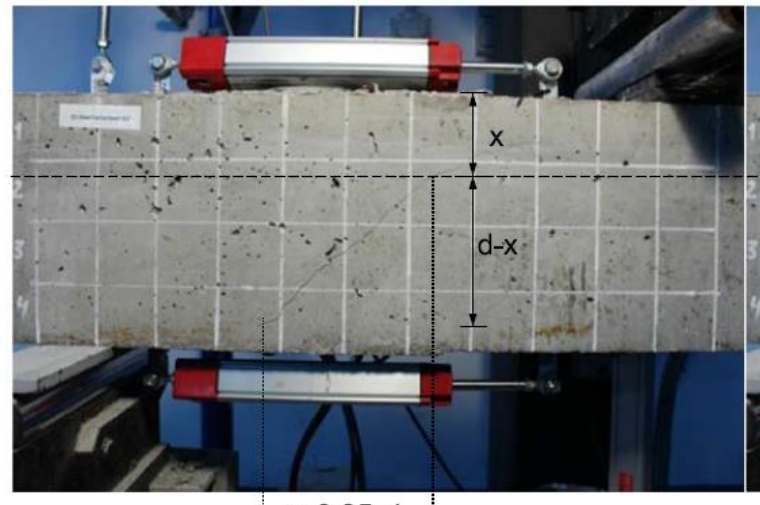

$\approx 0.85 d$

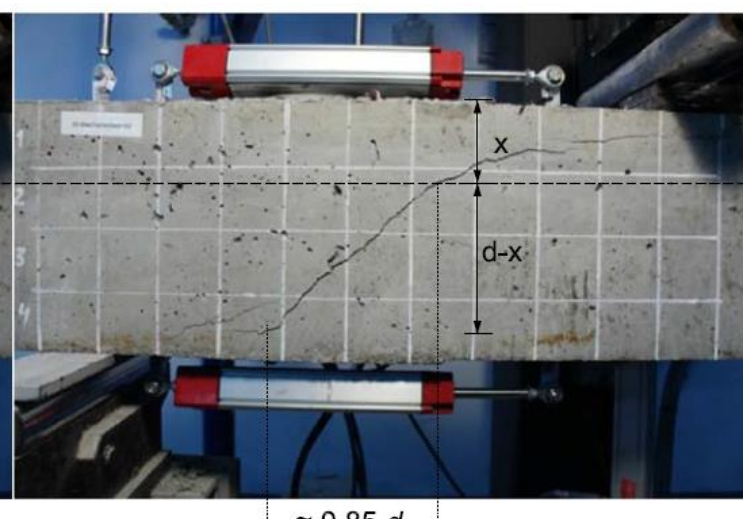

$\approx 0.85 d$

Fig. 1. Critical shear crack evolution and horizontal projection of the first branch of this crack.

A main assumption of the model is to consider that failure occurs when, at any point of the compression chord, the principal stresses $\left(\sigma_{1}, \sigma_{2}\right)$ reach the Kupfer's biaxial failure envelope [31], in the compression-tension branch (Fig. 2). This assumption is based on the experimental observation that when this happens, the concrete in the compression chord, subjected to a multiaxial stress state, initiates softening, reducing its capacity as the crack propagates.

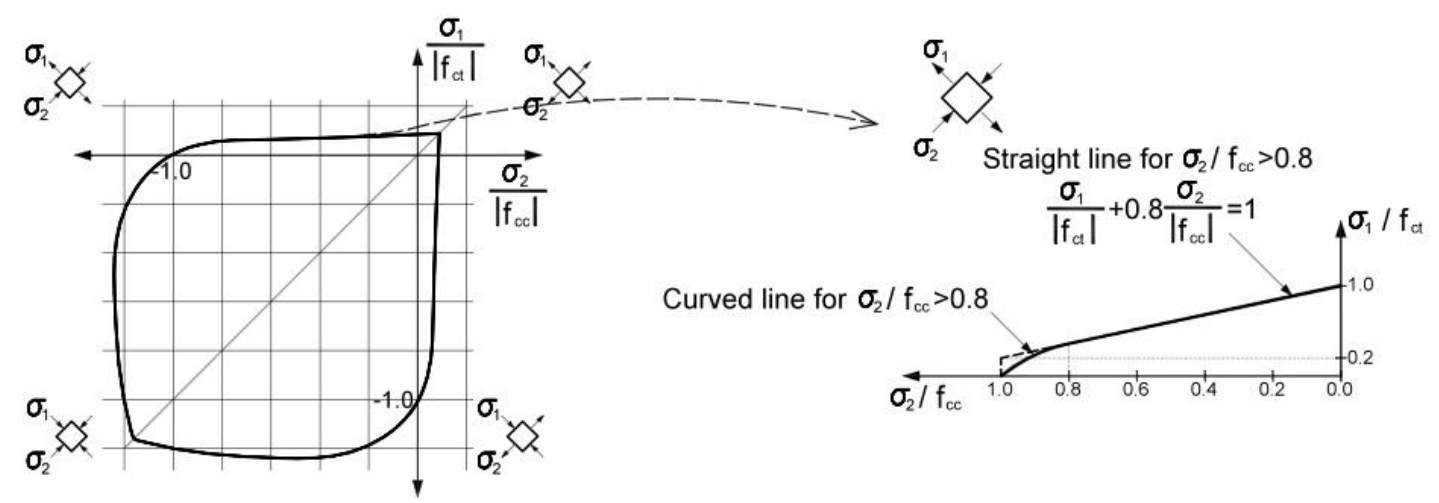

Fig. 2. Adopted failure envelope for concrete under a biaxial stress state. Adapted from [31].

When the load is increasingly applied, flexural cracks successively appear as the bending moment increases. It is assumed that the critical crack is the closest crack to the zero bending moment point and that it starts where the bending moment diagram at failure reaches the cracking moment of the cross section. The critical section, where failure occurs, is assumed to be located where the critical crack reaches the neutral axis depth. This assumption is justified because any other section closer to the zero bending moment point has a bigger depth of the compression chord, produced by the inclination of the strut and will resist a higher shear force. On the other hand, any other section placed between this section and the maximum moment 
section will have the same depth of the compression chord but will be subjected to higher normal stresses and, therefore, the uncracked concrete zone will have a higher shear transfer capacity.

Moreover, based also on experimental observations made by the authors and summarized in [24], the horizontal projection of the first branch of the flexural-shear critical crack is considered to be equal to $0.85 d$ (Fig. 1). This is equivalent to considering that its inclination is approximated as in Eq. (12), shown in Table 1.

As a result of the above assumptions, the distance between the zero bending moment point and the initiation of the critical crack is $s_{c r}=M_{c r} / V_{u}$, and the position of the critical section will be $s_{u}=s_{c r}+0.85 d_{s}$, which is usually a little higher than $d_{s}$. This is the reason why for design purposes, $d_{s}$ is adopted as the position of the section where shear strength must be checked for $\mathrm{RC}$ members. In prestressed concrete members, the cracking moment is higher and the position of the critical crack is shifted away from the zero bending moment point with respect to RC members. For this reason it is proposed that the shear strength is checked at a section placed at a distance $d_{s}\left(1+0.4 \sigma_{c p} / f_{c t m}\right)$. The higher cracking moment in a prestressed concrete section, with respect to a reinforced concrete section, is taken into account in the background mechanical model by means of the strength factor $K_{p}$ (Eq. 10 in Table 1$)$. The complete derivation of this term can be found in reference [25]. In case of reinforced concrete beams without axial loads, $P$ $=0$, the factor $K_{p}$ becomes equal to 1 .

Figure 3 plots, in a schematic way, the different contributing actions in the proposed model (Fig. 3a-3b) and compares them with the contributing actions in the Level III of Approximation of Model Code 2010 [32] (Fig. 3c), derived from both the Modified Compression Field Theory [13] and the Generalized Stress Field Approach [33], and the steel contribution of a variable angle truss model (Fig. 3d), as the one given in EC2 [4] for members with shear reinforcement. The different models are not contradictory; in fact, the fundamental difference is that they have been derived from different simplifying assumptions. The model 
developed by the authors considers that the maximum load occurs slightly after the first branch of the critical crack reaches the neutral axis depth, as also proposed by [34]. Other models take into account the full crack development. When the second branch of the critical crack is developed, the aggregate interlock in the first branch is activated. It could be understood that the shear transferred by the non-cracked concrete zone in this model (Fig. 3a-3b) is approximately equal to the contributing actions in the other models that takes place after the development of the second branch of the critical crack (aggregate interlock or stirrups crossing that zone). Note that the angle $\theta$ in Fig. 3a-3c is the angle of the critical crack, and it is an angle fixed by the assumptions carried out in the models. However, the angle $\theta$ in Fig. $3 \mathrm{~d}$ is the angle of the compression field, an equilibrium angle that can be chosen by the designer.

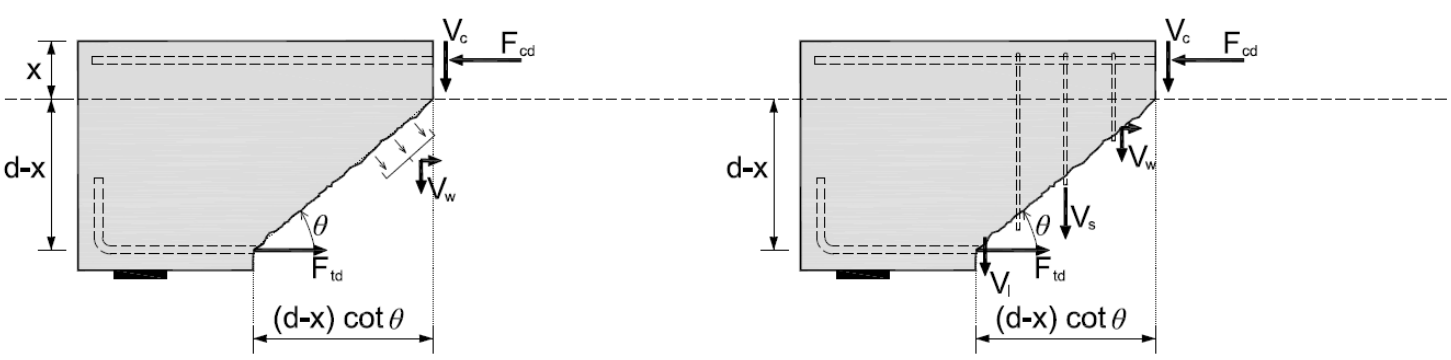

a)

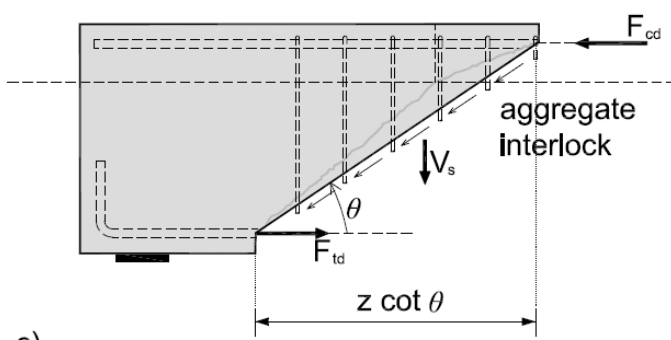

c)

Fig. 3. Shear contributing actions at failure. a)Background mechanical model for elements without stirrups. b) Background mechanical model for elements with stirrups. c)Model Code 2010 model. d) Variable angle truss model.

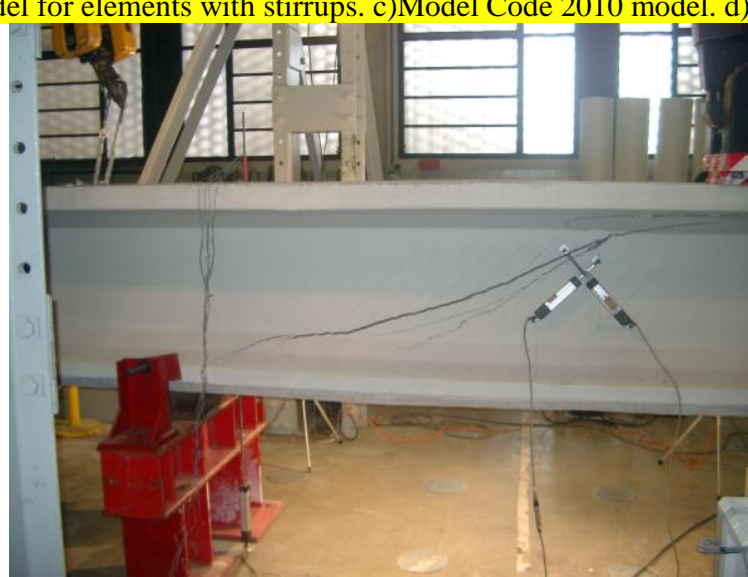

Fig. 4. Crack pattern at failure in a prestressed concrete girder without flexural cracks $[35,36]$. 
In case of highly prestressed simply supported concrete beams, such as some T or I beams, usually with thin webs and with minimum or no shear reinforcement, no flexural cracks take place near the supports. In these regions, the beam web is subjected to high shear stresses, combined with normal compressive stresses produced by prestressing, generating a biaxial compression-tension state of stress. When, at the most stressed point of the web, the principal stresses reach the biaxial failure envelope, a diagonal crack initiates, which develops through the entire beam height (Fig. 4). In this situation, the model given by Eqs. (1)-(12) is not valid, as the main assumption of the initial bending crack would be false. The derivation of a design expression according to Mohr's circle of stresses assuming Kupfer's biaxial failure surface as failure criteria is carried out in [25].

In the case of PC beams with shear reinforcement, once the web cracks, stirrups start working and a shear force higher than the cracking shear can be resisted [37]. Therefore, higher bending moments take place near the supports which, generally, will produce flexural cracks. For this reason, in PC members with shear reinforcement, it is assumed that the shear strength may be computed accepting flexural cracks, by means of the model described by Eqs. (1)-(12), independently of the origin (bending or shear) of the initial crack.

\section{Derivation of the simplified equations considering shear- flexure interaction}

\subsection{General and minor changes to simplify the procedure}

The background mechanical model has been presented in the previous section. However, for design purposes, some simplifications are necessary in order to make the model easier to use in daily engineering practice. Taking into account that when shear-flexure failure takes place, both the residual tensile stresses, $v_{w}$ (Eq. 4), and the dowel action, $v_{l}$ (Eq. 5), are small compared to the shear resisted by the uncracked zone, $v_{c}$ (Eq. 3), the two first mentioned contributing actions, $v_{w}$ and $v_{l}$ have been incorporated into $v_{c}$ (Eq. 3). The detailed derivation of the new compact expression may be seen in Appendix A1. The resulting equation is presented in Eq. (13): 


$$
V_{u}=\left(v_{c}+v_{w}+v_{l}\right) f_{c t m} \cdot b \cdot d+V_{s}=0.30 \zeta \frac{x}{d} f_{c k}^{2 / 3} b_{v, e f f} d+V_{s}\left[1+\Delta_{V c u}\right]
$$

where all parameters have been defined previously and $\Delta_{\mathrm{V} c u}$ is a non-dimensional confinement factor which considers the increment of the shear resisted by the concrete caused by the stirrup confinement in the compression chord, as shown in Eq. (14). This parameter will be taken constant and equal to 0.4 for simplicity reason in the type-code expression, although its actual value is generally between 0.2 and 0.6 for normal members.

$$
\Delta_{V c u}=0.5 \zeta\left(1+\frac{b}{b_{w}}\right) \frac{x}{d} \frac{b_{v, e f f}}{b} \approx 0.4
$$

Note that the influence of normal forces in Eq. (13) is taken into account by the parameter $x / d$. As can be seen in Appendix A1, the strength factor $K_{p}$, which takes into account the higher cracking moment in a prestressed concrete section with respect to a reinforced concrete section, has been considered equal to 1.0 due to the relatively low influence of this parameter and for simplicity reasons.

Eq. (13) depends on the neutral axis depth ratio, $x / d$. This value may be computed from Eq. (7) for RC beams disregarding the compression reinforcement, but it may be also simplified as proposed in Eq. (15). Both values are represented in Figure 5. Consequently, the model considers the influence of the amount of the longitudinal tensile reinforcement in an indirect way, through the variation of the neutral axis depth. An increase of the amount of the longitudinal reinforcement would increase the neutral axis depth, increasing the shear strength and decreasing the inclination of the critical crack, Eq. (12). The longitudinal compression reinforcement is disregarded in Eq. (15) because its effect decreasing the neutral axis depth is compensated by the increase of the shear strength caused by the presence of steel in the concrete compression chord.

$$
\frac{x_{0}}{d}=\alpha_{e} \rho_{l}\left(-1+\sqrt{1+\frac{2}{\alpha_{e} \rho_{l}}}\right) \approx 0.75\left(\alpha_{e} \rho_{l}\right)^{1 / 3}
$$




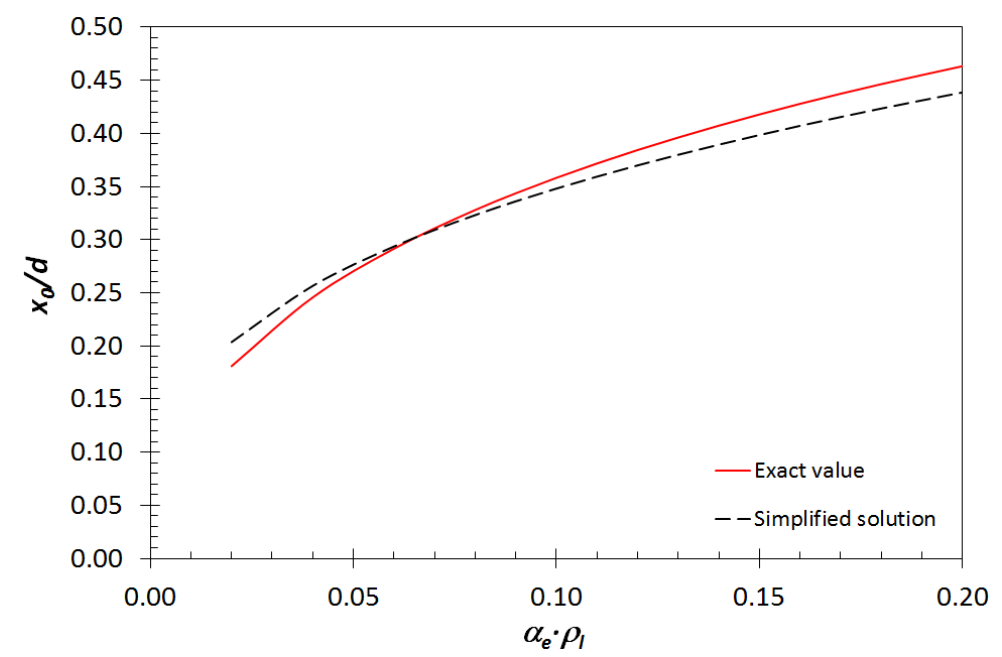

Fig. 5. Exact value of the neutral axis depth ratio and simplified expression given in Eq. (15).

Eq. (13) has been derived taken into account that, in most beams, the residual tensile stresses, $v_{w}$, and the dowel action, $v_{l}$, are small compared to the shear resisted by the uncracked zone, $v_{c}$. However, in some members, e.g. one-way slabs with low levels of longitudinal reinforcement and without stirrups, this assumption would lead to too conservative results, as the dimensionless shear contribution due to residual stresses along the crack may be comparable to the contribution of the uncracked zone, since $x / d$ is small. In this situation, it is possible to derive an equation for the minimum shear strength, $V_{c u, \min }$, that takes explicitly into account the residual tensile stresses action. This expression will be very useful for elements with low amounts of longitudinal reinforcement, and its derivation may be found in Appendix A2. The resulting equation for this minimum shear strength is given by Eq. (16), in which $x / d$ shall not be taken higher than 0.20 .

$$
V_{c u, \min }=\left(v_{c}+v_{w}\right) f_{c t m} \cdot b \cdot d \approx 0.25\left(\zeta \frac{x}{d}+\frac{20}{d_{0}}\right) f_{c k}^{2 / 3} \cdot b_{w} d
$$

The influence of the compression flange is taken into account in the general model by means of the effective shear width given by Eqs. (9a - 9b). In the case in which $x>h_{f}$, Eq. (9b), the effective width shall be interpolated between the web width, $b_{w}$, and the effective width in the compression flange, $b_{v}$ (Eq. 9a). Equation (9b) is a straight forward equation, but the authors have considered that it is too complex for everyday engineering. For that reason, the following simplified expression for the calculation of the effective width is proposed: 


$$
\begin{aligned}
& \text { if } x \leq h_{f} \rightarrow b_{v, e f f}=b_{v}=b_{w}+2 h_{f} \leq b \\
& \text { if } x>h_{f} \rightarrow b_{v, \text { eff }} \approx b_{w}+\left(b_{v}-b_{w}\right)\left(\frac{h_{f}}{x}\right)^{3 / 2}
\end{aligned}
$$

Eqs. (9a-9b) and (17a-17b) are compared in Figure 6 for some T-beams with compression flanges. The results shown that the error between the original formulation and the simplification is generally lower than $10 \%$.

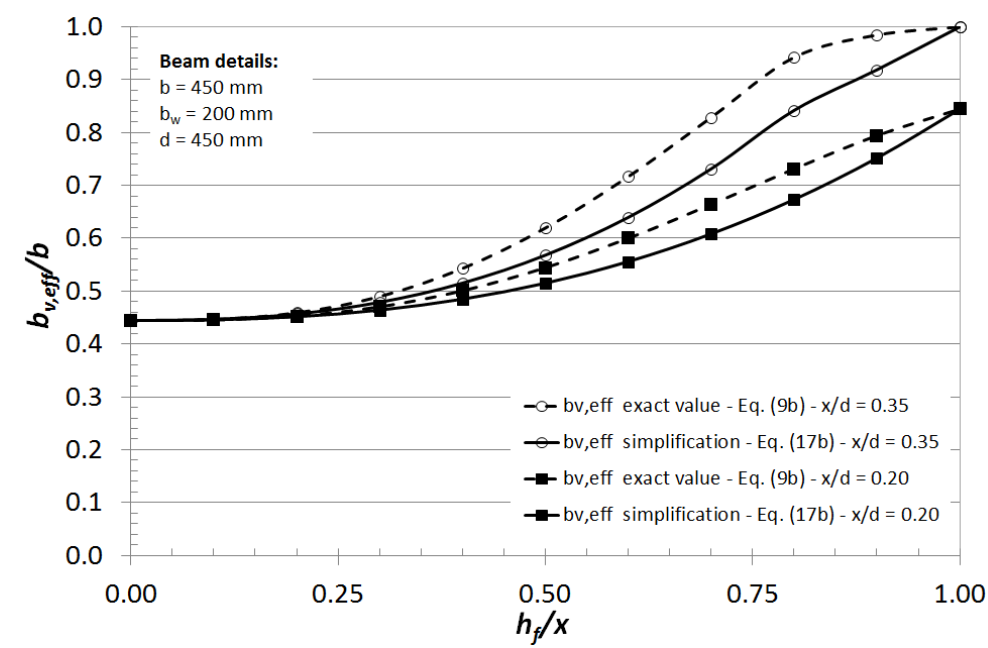

Fig. 6. Comparison between exact and simplified relative effective width for shear strength calculations.

\subsection{Size effect}

Due to the brittle character of the failure that takes place when the second branch of the critical crack propagates, it is necessary to take into account the size effect. The empirical factor proposed by other authors [22] was adopted in the background mechanical model, by means of the term $\zeta$, Eq. (11), which can be assimilated to the size effect of a splitting test. According to such model, the size effect on the shear failure of slender beams seems to depend on the size of the shear span $a$, that would be proportional to the diameter of the specimen of a hypothetical splitting test that occurs at the beam compression chord, between the point where the load is applied and the tip of the first branch of the critical shear crack. The term given by Eq. (11) was derived from a previous experimental work carried out by Hasegawa et al. [38], in which a linear relationship was proposed for the size effect. However, this work was lately re-examined 
by Bažant et al. [39], suggesting that the splitting tensile strength followed the size effect term developed by fracture mechanics with an asymptote, as shown in Eq. (18):

$$
\sigma_{\mathrm{N}}=\max \left(\frac{\mathrm{Bf}_{t}^{\prime}}{\sqrt{1+\beta_{0}}}, \sigma_{\mathrm{y}}\right)
$$

Where $f_{t}^{\prime}$ is a measure of material tensile strength, $\beta_{0}$ is proportional to the diameter of the cylinder, $B$ is an empirical constant and $\sigma_{y}$ is the asymptote.

Moreover, the shear strength of structural concrete members is affected, not only by the element size, but also by its slenderness, $a / d$, as reported by many researchers [40-42]. For the previous reasons, a new empirical size effect term is proposed which depends on $d$ and $a / d$. The factor depending on $d$ will be taken as the factor proposed by ACI Committee 446 [43], Eq. (19), which is an expression similar to the one on the left inside the parenthesis in Eq. (18).

$$
v_{c}=\frac{v_{0}}{\sqrt{1+\frac{d}{k_{d}}}}
$$

The factor depending on $a / d$ will be taken from the empirical work performed with genetic programming in $[44,45]$, where was seen that the term $a / d^{0.21}$ correctly predicted the influence of this variable. The new combined size and slenderness effect factor is given in Eq. (20). Figure 7 compares Eq. (20) with previous size effect factor given by Eq. (11).

$$
\zeta=\frac{2}{\sqrt{1+\frac{d_{0}}{200}}}\left(\frac{d}{a}\right)^{0.2} \nless 0.45
$$

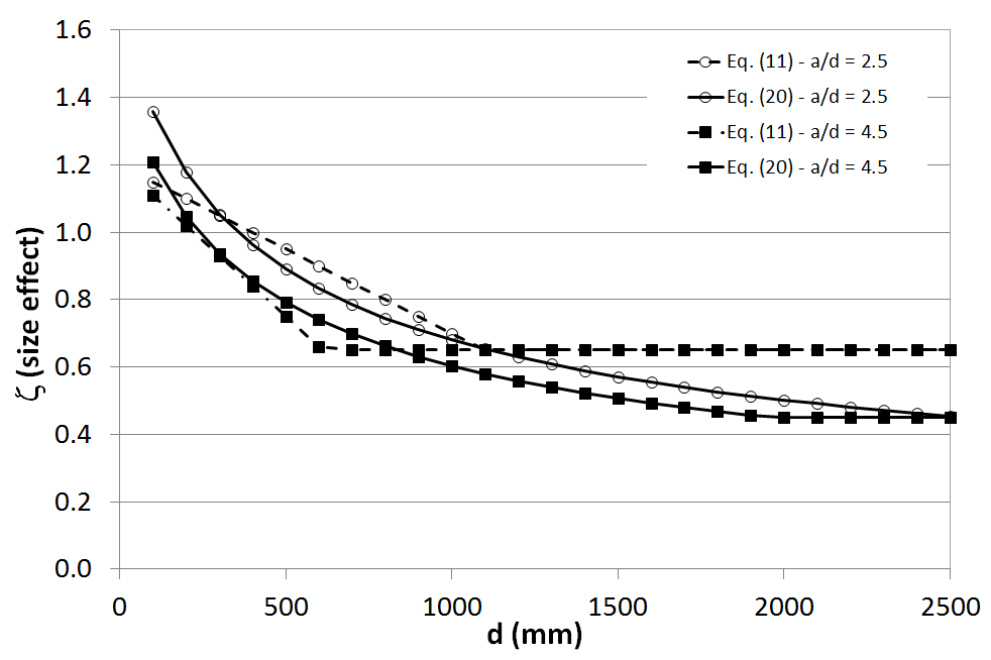

Fig. 7. Comparison between size effect term given by Eq. (11) and new size effect term given by Eq. (20). 


\section{Simplified shear model}

Based on the previous theoretical multi-action model and on the main simplifications presented in the previous section, the following model is proposed for shear design and assessment in engineering practice.

\subsection{General}

The design shear force in the section considered, $V_{E d}$, results from external loading $\left(V_{E d, 0}\right)$ and prestressing (bonded or unbonded, considered as an external action (Figure 9)).

$$
V_{E d}=V_{E d, 0}-P \cdot \sin \delta_{p}
$$

When, on the basis of the design shear calculation, no shear reinforcement is required, minimum shear reinforcement should nevertheless be provided. The minimum shear reinforcement may be omitted in members such as slabs (solid, ribbed or hollow core slabs) and footings where transverse redistribution of loads is possible. Minimum reinforcement may also be omitted in members of minor importance (e.g. lintels with span $\leq 2 \mathrm{~m}$ ) which do not contribute significantly to the overall resistance and stability of the structure.

The longitudinal tension reinforcement should be able to resist the additional tensile force caused by shear, given by Eq. (29).

Where a load is applied near the bottom of a section, sufficient vertical reinforcement to suspend the load to the top of the section should be provided in addition to any reinforcement required to resist shear.

\subsection{Simplified shear design and assessment equations: the}

\section{compression chord capacity model}

The design procedure of members with or without shear reinforcement shall verify equilibrium and shall take into account the influence of the stresses transferred across cracked concrete $\left(V_{w}\right.$ in Figure 8), by the compression chord $\left(V_{c}\right)$, and the contribution of the shear reinforcements $\left(V_{s}\right)$ and longitudinal reinforcements $\left(V_{l}\right)$. 
Shear strength shall be checked at least at a distance $d_{s}\left(1+0.4 \sigma_{c p} / f_{c t m}\right)$ from the support axis and at any other potential critical section, where $\sigma_{c p}=N_{E d} / A_{c}$ is the mean concrete normal stress due to axial loads or prestressing (compression positive) and $f_{c t m}$ is the mean concrete tensile strength, not greater than 4.60 MPa. See Appendix A3 for further information regarding the location of the critical section.

The inclination of the compression strut is considered equal to the mean inclination of the shear crack, computed as follows

$$
\cot \theta=\frac{0.85 d_{s}}{d_{s}-x} \leq 2.50
$$

where $x$ is the neutral axis depth of the cracked section, obtained assuming zero concrete tensile strength. For reinforced concrete members without axial loads, $x=x_{0}$ (see Eq. 15).
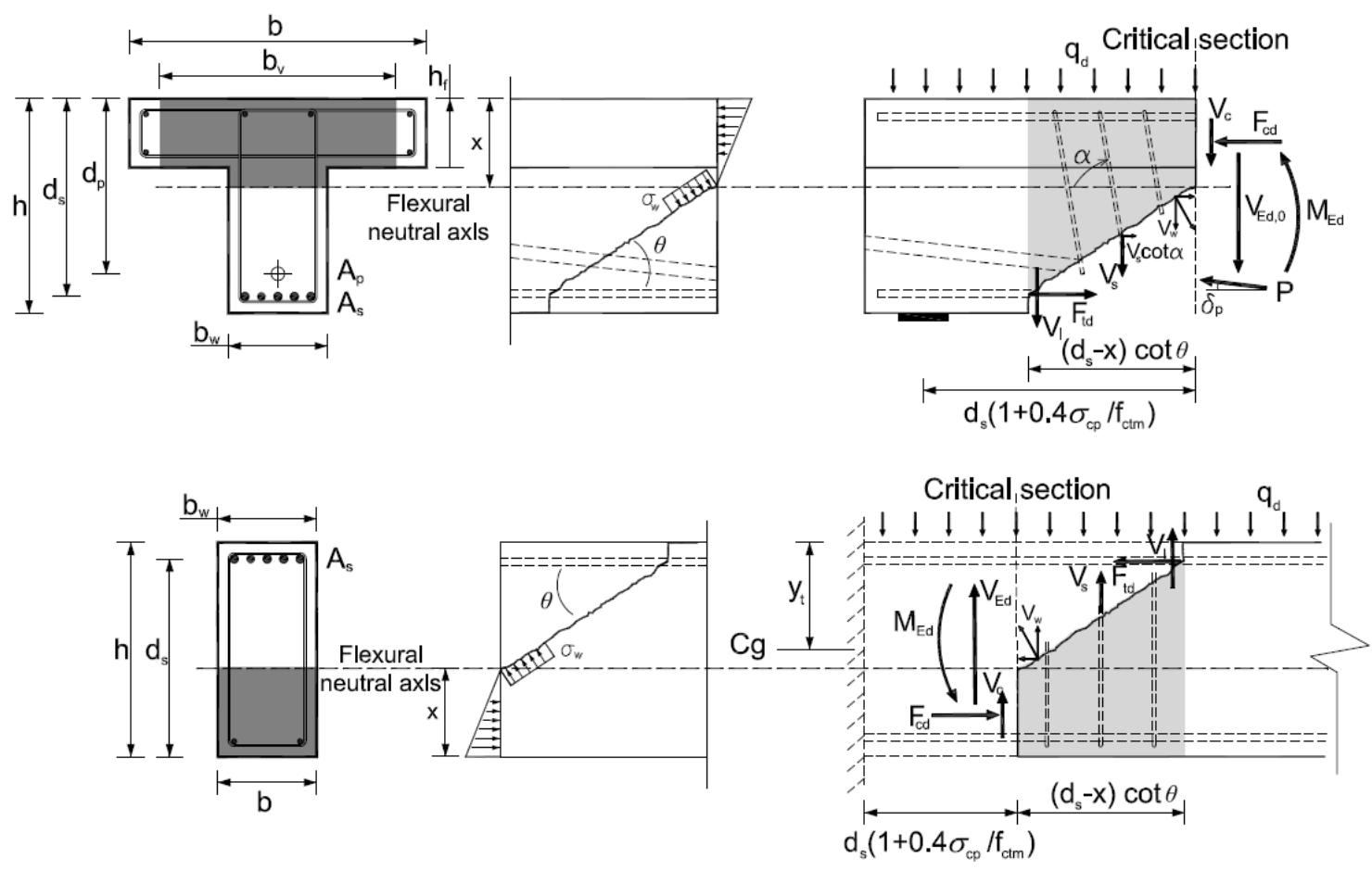

Fig. 8. Shear contributions and notation for simple supported beam and cantilever beam.

For prestressed or axially loaded members ( $N_{E d}$, compression positive), $x$ can be estimated, in a simplified manner, by means of Eq. (23). Note that for compressed members $\left(N_{E d} \geq 0\right)$, the right side of the equation incorporates a reducing factor 0.8 which is not present in the equivalent expression of the background theoretical model, see Eq. (8). This factor is needed to correct the fact that in the derivation of the simplified value of the shear strength, Eq. (13) 
and Appendix A1, mean values of the contributing actions $v_{w}$ and $v_{l}$ have been added to $v_{c}$.

However, $v_{w}$ and $v_{l}$, should not be affected by the variation of the neutral axis depth for prestressed beams, and for this reason the reduction factor is needed. Moreover, it can be also seen as a calibration factor to increase safety when compressive axial loads are present. It is also important to highlight that the increase of the neutral axis depth depends on the ratio

$\frac{\sigma_{c p} / f_{c t m}}{\sigma_{c p} / f_{c t m}+1}=\frac{\sigma_{c p}}{\sigma_{c p}+f_{c t m}}$ and not only on $\sigma_{c p}$.

$$
\begin{aligned}
& N_{E d} \geq 0 \rightarrow x=x_{0}+0.80\left(h-x_{0}\right)\left(\frac{d}{h}\right) \frac{\sigma_{c p}}{\sigma_{c p}+f_{c t m}} \leq h \\
& N_{E d}<0 \rightarrow x=x_{0}\left(1+0.1 \frac{N_{E d} d_{s}}{M_{E d}}\right) \geq 0
\end{aligned}
$$

The shear strength, $V_{R d}$, is the smaller value given by Eqs. (24) and (25).

$$
\begin{aligned}
& V_{R d}=V_{c u}+V_{s u} \\
& V_{R d, \max }=\alpha_{c w} b_{w} z v_{1} f_{c d} \frac{\cot \theta+\cot \alpha}{1+\cot ^{2} \theta}
\end{aligned}
$$

where $V_{c u}$ is the shear resisted by the concrete considering the different contributions given in Figure $8\left(V_{c u}=V_{c}+V_{l}+V_{w}\right)$, see Eq. (26). An alternative code type expression for $V_{c u}$ using the typical values of $f_{c t}$ and $E_{c}$ given in the ACI318-11 Code is presented in the on-line Supplementary Material.

$$
V_{c u}=0.3 \zeta \frac{x}{d} f_{c d}^{2 / 3} b_{v, \text { eff }} d \nless V_{c u, \min }=0.25\left(\zeta K_{c}+\frac{20}{d_{0}}\right) f_{c d}^{2 / 3} b_{w} d
$$

And $V_{s u}$ the shear resisted due to the shear reinforcement:

$$
V_{s u}=1.4 \frac{A_{s w}}{s} f_{y w d}\left(d_{s}-x\right) \sin \alpha(\cot \theta+\cot \alpha)
$$

$\zeta \quad$ is a combined size and slenderness effect factor, given by Eq. (20).

The parameter $b_{v, \text { eff }}$ shall be calculated using Eqs. (17). For the determination of $f_{c d}$ for Eq. (26), $f_{c k}$ shall not be taken greater than $60 \mathrm{MPa}$. This limitation is provided due to the larger observed variability in shear strength of members with higher strength concrete, particularly for members without stirrups such as slabs, as recognized for example in Model Code 2010 [32]. $K_{c}$ is equal to the relative neutral axis depth, $x / d$, but not greater than 0.20 when computing $V_{c u, m i n}$ (Eq. 26). The constant 1.4 is not a calibration factor, but a term to take into account the 
confinement of the concrete in the compression chord caused by the stirrups, as shown in Eq.

(14). The rest of terms can be seen in the notations.

Shear reinforcement is necessary when the shear design force exceeds the shear resisted by the concrete without shear reinforcement given by Eq. (26). Then, the necessary shear reinforcement is:

$$
\frac{A_{s w}}{s_{t}}=\frac{V_{E d}-V_{c u}}{1.4 f_{y w d}\left(d_{s}-x\right) \sin \alpha(\cot \theta+\cot \alpha)}
$$

The additional tensile force, $\Delta F_{\mathrm{td}}$, in the longitudinal reinforcement due to the shear force $V_{\mathrm{Ed}}$ may be calculated from:

$$
\Delta F_{t d}=V_{E d} \cot \theta-0.5 \cdot V_{s u}(\cot \theta+\cot \alpha)
$$

The tensile force of the longitudinal reinforcement, $\left(M_{\mathrm{Ed}} / z\right)+\Delta F_{\mathrm{td}}$, should be taken not greater than $M_{\mathrm{Ed}, \max } / z$, where $M_{\mathrm{Ed} \text {,max }}$ is the maximum moment along the beam. In elements with inclined prestressing tendons, longitudinal reinforcement at the tensile chord should be provided to carry the longitudinal tensile force due to shear defined by Eq. (29). See Appendix A4 for the details regarding the derivation of Eq. (29).

In prestressed members without shear reinforcement, the shear resistance of the regions uncracked in bending in ULS may be obtained using a design expression directly derived from Mohr's circle of stresses [25], as previously commented in Section 2.

\section{Verification of the model and comparison with other formulations}

The shear strength predictions of all tested beams included in the four databases developed by ACI-DafStb for RC and PC beams [26-28] by the simplified proposal presented in Section 4 and by four current structural codes are compared in Table 2 and Figure 9. All explicit partial safety factors have been removed from the original formulations, and the mean value of the materials strength has been used for these calculations. The proposed model correlates significantly better with the tests results than any of the four considered code formulations. In summary, for the 1285 tested beams, the average of the $V_{\text {tes }} / V_{\text {pred }}$ ratio is 1.17 for the simplified 
equations. For the ACI318-11 provisions the ratio equals 1.44, 1.26 for EC-2, 1.35 for Model Code 2010 and 1.33 for CSA A23.3-14, using for the Model Code the better results obtained for the different levels of approximation. The $\mathrm{CoV}$ is $18.6 \%$ for the simplified model proposed in this paper. For ACI318-04, EC-2, MC- 2010 and CSA A23.3-14 the CoV equals 35.3\%, 34.1\%, $31.4 \%$ and $26.9 \%$ respectively. A recently published paper studied the scatter in the shear capacity of slender RC members without web reinforcement [46]. The authors concluded that the scatter of the shear capacity seems to be mainly due to the randomness of the tensile strength of concrete. Also recently, other authors confirmed that a comparison with different shear design models revealed that models that use the concrete tensile strength predict the shear capacity of continuous prestressed concrete beams with external prestressing more accurately [47] that the models that do not explicitly consider the tensile strength of the concrete. In this sense, the coefficient of variation of the predictions by the Compression Chord Capacity Model for the beam tests included in the four databases is not much higher than the coefficient of variation of the splitting tensile strength. In a published database of 78 splitting tensile tests [48], the coefficient of variation (COV) for the prediction of the tensile strength was $15.1 \%$. This fact seems to indicate that the shear transfer mechanisms at failure have been well captured by the model.

Table 3 presents a more detailed comparison between the simplified proposal and the EC2 formulation, comparing the results obtained considering the mean value of the materials strength, the characteristic value for concrete strength without partial safety factors and including them $\left(\gamma_{c}=1.50 ; \gamma_{s}=1.15\right)$. The results show that, for the studied databases, the proposal shows a reasonable and homogeneous safety level.

The predictions obtained by means of the proposed formulation, EC-2 and MC-2010 are compared in Fig. 10-11 with some selected series of tests [49-56]. Note that the code format proposal captures the influence of the different parameters studied: $d, A_{s w} f_{y w}$ and $\sigma_{c p} / f_{c t m}$ both for RC and PC members. 


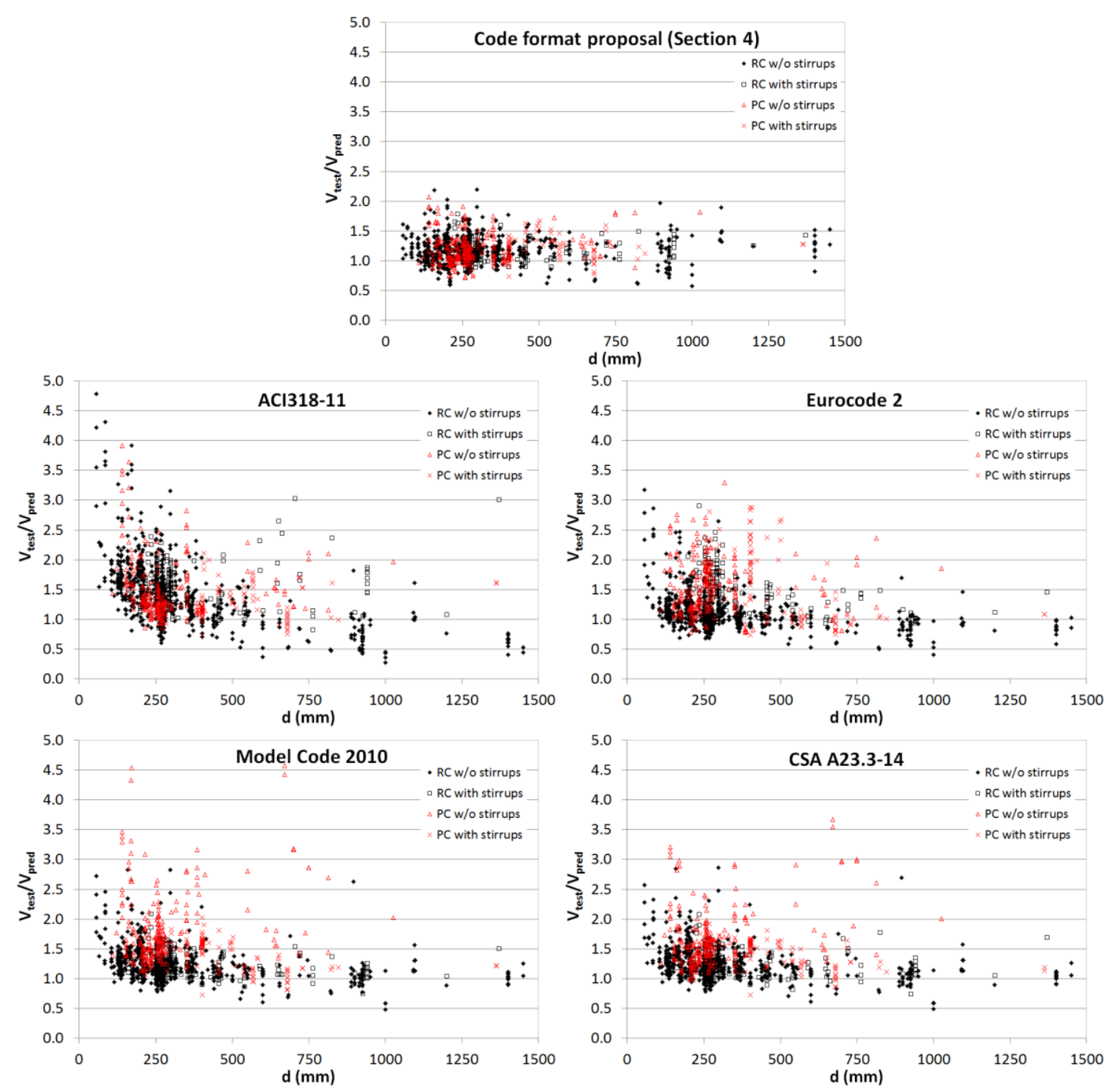

Fig. 9. Correlation between the predictions and the experimental results as a function of the effective depth, $d$, for the 1285 beams included in the four ACI-DafStb databases 
A)

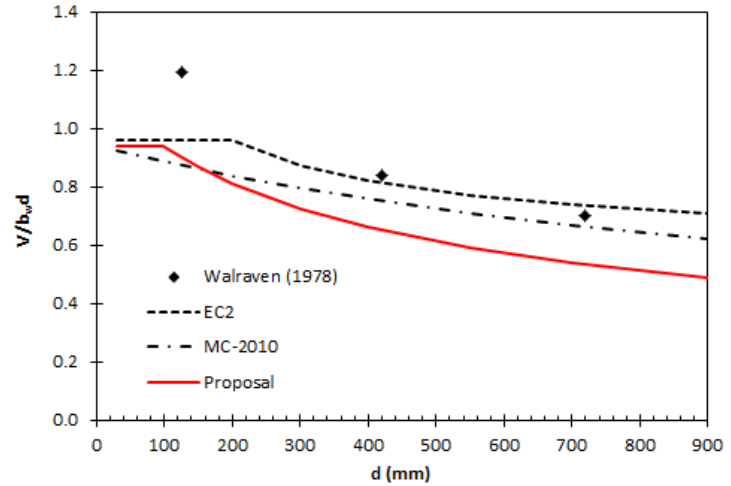

C)

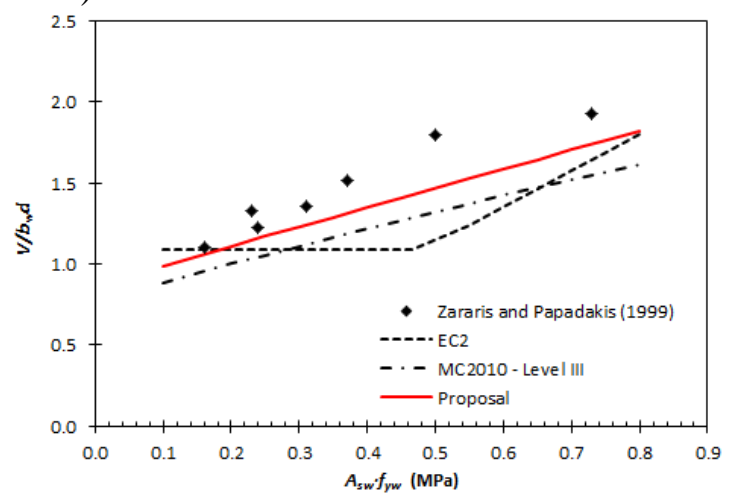

B)

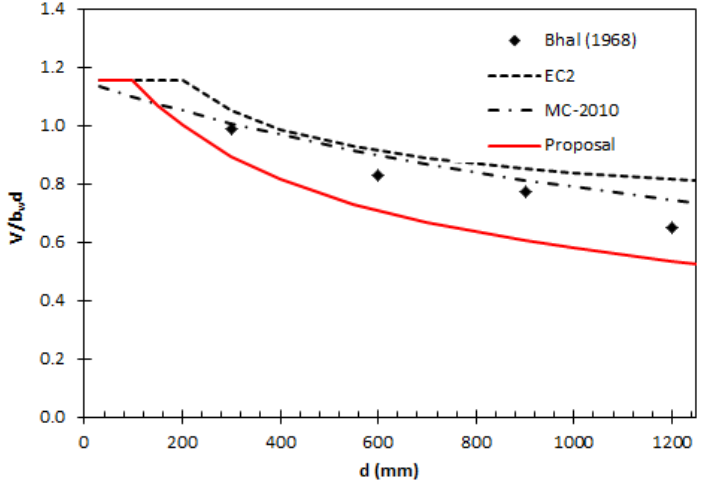

D)

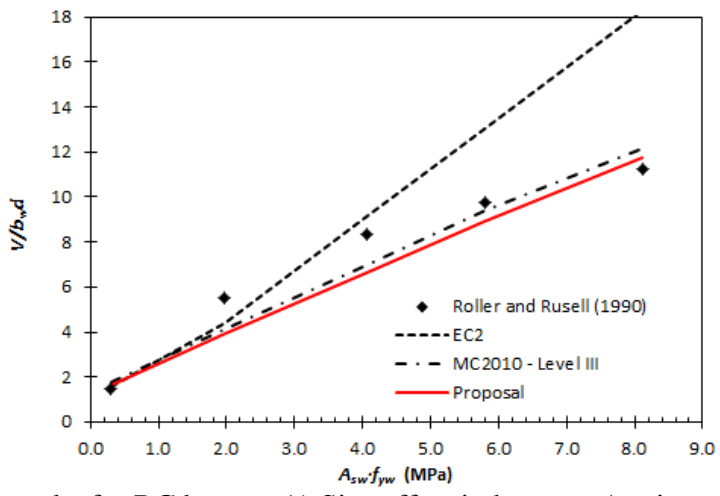

Fig. 10. Correlation between the prediction and experimental results for RC beams: A) Size effect in beams w/o stirrups [49]. B) Size effect in beam w/o stirrups [50]. C) Influence of the stirrup index [51]. D) Influence of the stirrup index [52].
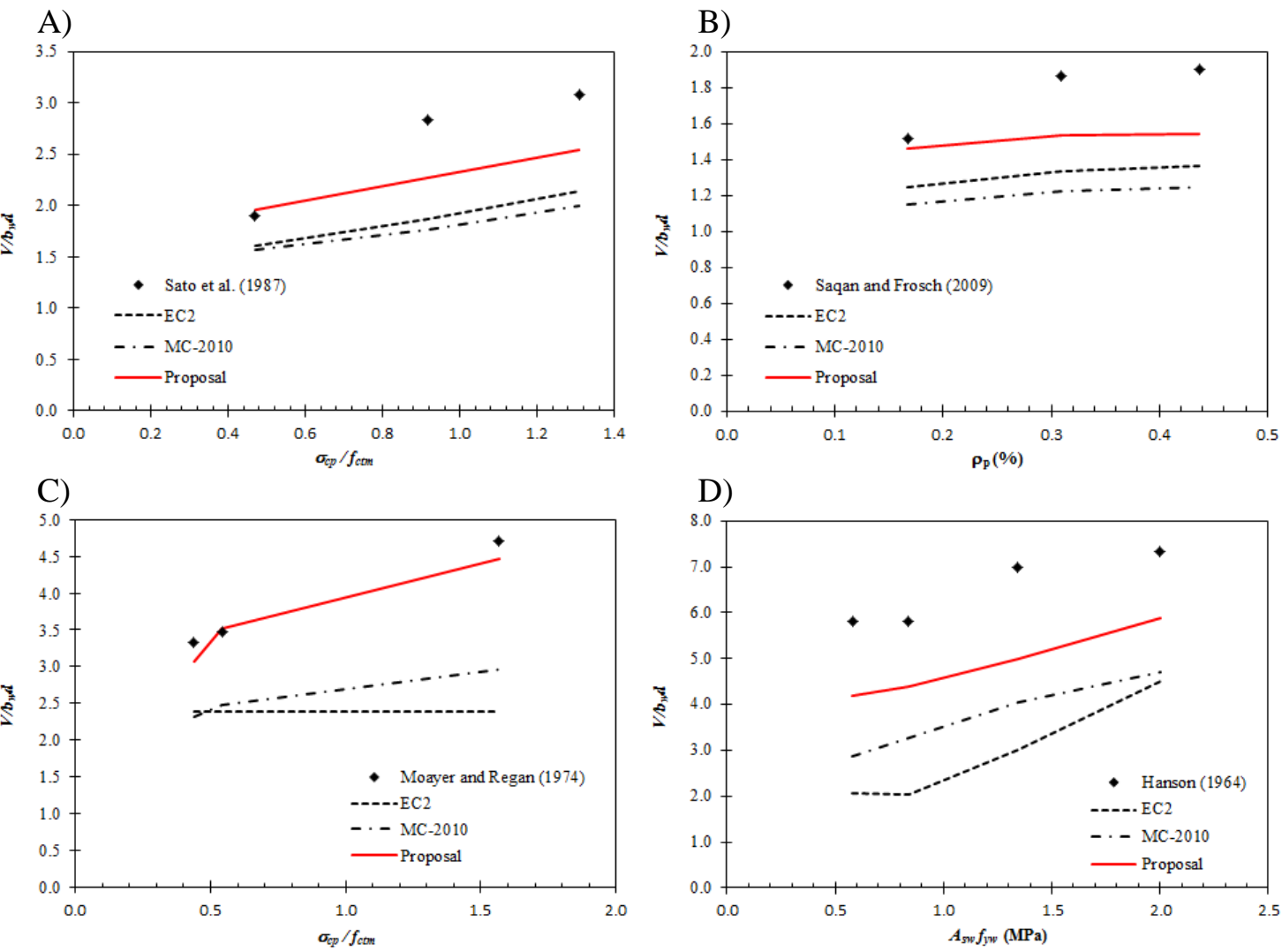

Fig. 11. Correlation between the prediction and experimental results for PC beams: A) Influence of prestressing ratio $\sigma_{c p} / f_{c t m}$ in beams w/o stirrups [53]. B) Influence of amount of prestressing reinforcement for constant prestressing force in beams w/o stirrups [54]. C) Influence of prestressing ratio $\sigma_{c p} / f_{c t m}$ in beams with stirrups [55]. D) Influence of the stirrup index [56]. 


\section{Application example}

\subsection{Reinforced concrete slab}

The shear strength of a continuous RC ribbed slab, of two equal spans of $8 \mathrm{~m}$ each, subjected to a permanent load of $5.0 \mathrm{kN} / \mathrm{m}^{2}$ and a live load of $8.0 \mathrm{kN} / \mathrm{m}^{2}$, must be verified. The dimensions and reinforcement layouts are indicated in Figure 12. The design bending moments and shear forces distributions $\left(\gamma_{G}=1.35, \gamma_{Q}=1.50\right)$ in a strip of $0.80 \mathrm{~m}$ width (distance between ribs axes), when the live load is applied in the whole length of both spans are shown in Figure 13.

Concrete characteristic strength is $25 \mathrm{MPa}\left(\gamma_{c}=1.50\right)$, maximum aggregate size is 14 $\mathrm{mm}$. Yield strength of both longitudinal and transverse reinforcements is $500 \mathrm{MPa}\left(\gamma_{s}=1.15\right)$.
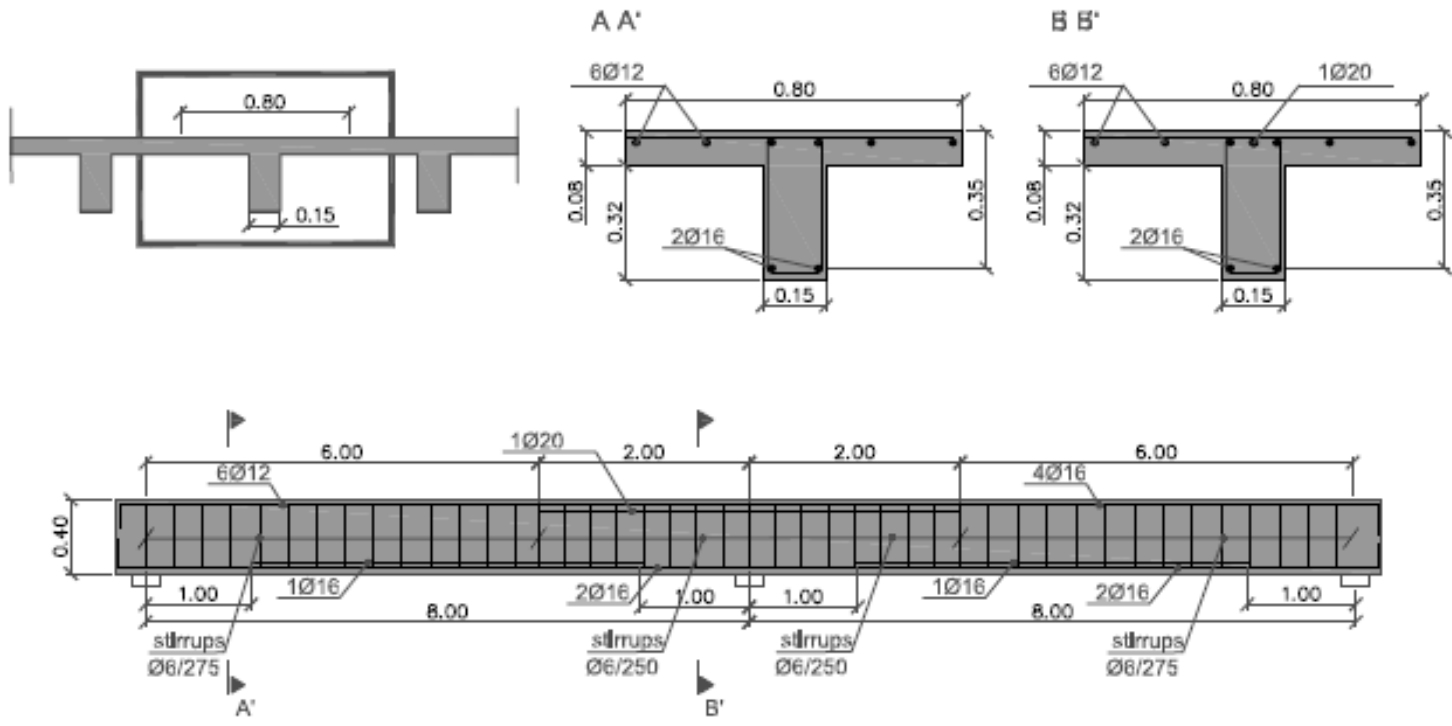

Fig. 12. Dimensions and reinforcement layouts.

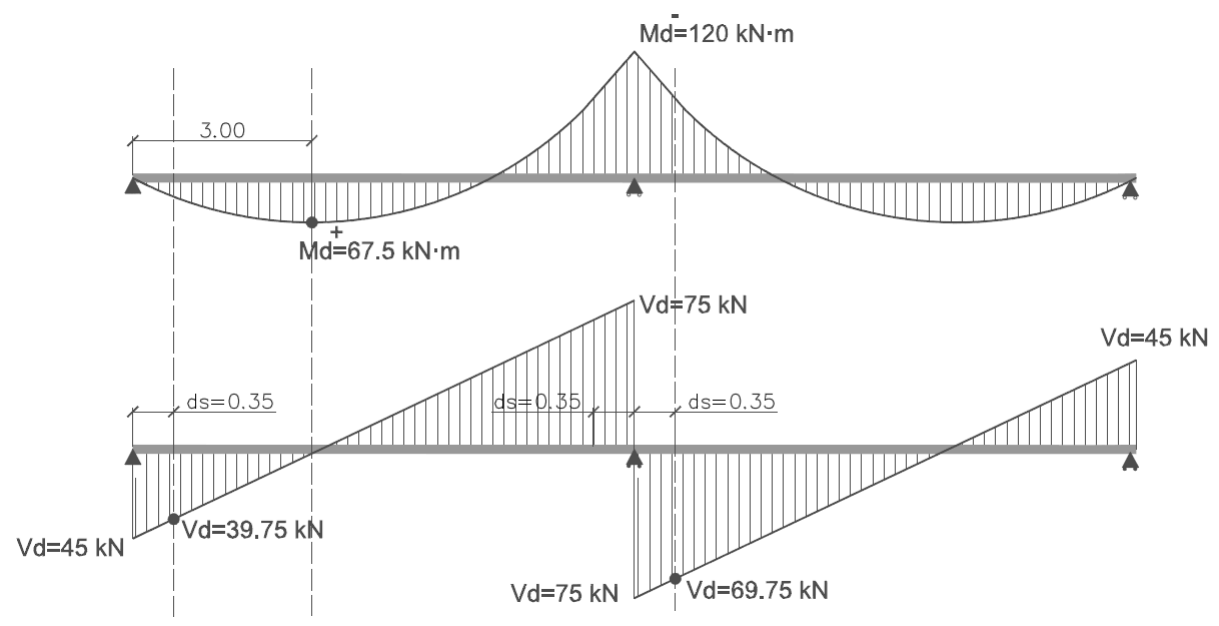

Fig. 13. Design bending moments and shear forces distributions $\left(\gamma_{G}=1.35, \gamma_{Q}=1.50\right)$. 
6.1.1 Verification of the shear strength near the end supports

Position of the control section: distance to support axis: $s=d_{s}=350 \mathrm{~mm}$

Design shear force $V_{E d}=45.0-0.35 \cdot 15=39.75 \mathrm{kN}$

Longitudinal reinforcement area: $2 \phi 16=402 \mathrm{~mm}^{2}$

Concrete properties and neutral axis depth:

$f_{c d}=\frac{f_{c k}}{\gamma_{c}}=16.67 \mathrm{MPa} ; f_{c t m}=0.30 \sqrt[3]{f_{c k}^{2}}=2.56 \mathrm{MPa}$

$E_{c}=22000\left(\frac{f_{c m}}{10}\right)^{0.3}=22000\left(\frac{33}{10}\right)^{0.3}=31475 \mathrm{MPa} \quad ; \alpha=\frac{E_{s}}{E_{c}}=6.35$

$\rho=\frac{A_{s}}{b d}=\frac{402}{800 \cdot 350}=0.00144 ; \quad \frac{x}{d}=0.75 \cdot(\alpha \rho)^{1 / 3}=0.157 ; \quad x=54.95 \mathrm{~mm}<h_{f}$

Note that $b$ is taken equal to the width of the compression flange (effective bending width).

$x<h_{f}=80 \mathrm{~mm} ; b_{v}=b_{w}+2 h_{f}=150+2 \cdot 80=310 \mathrm{~mm}$

Size effect: $a=0.20 L=1.6 m ; \zeta=\frac{2}{\sqrt{1+\frac{350}{200}}}\left(\frac{350}{1600}\right)^{0.2}=0.89$

$V_{c u}=0.3 \zeta \frac{x}{d} f_{c d}^{\frac{2}{3}} b_{v, e f f} d=0.3 \cdot 0.89 \cdot 0.157 \cdot 16.67^{\frac{2}{3}} \cdot 310 \cdot 350=29.7 k N \nless V_{c u, \min }$

$V_{c u, \min }=0.25\left(\zeta k_{c}+\frac{20}{d_{0}}\right) f_{c d}^{2 / 3} b_{w} d=0.25\left(0.89 \cdot 0.157+\frac{20}{350}\right) 16.67^{2 / 3} 150 \cdot 350$

$=16.9 \mathrm{kN}$

$\cot \theta=\frac{0.85 d_{s}}{d_{s}-x}=\frac{0.85 \cdot 350}{350-54.95}=1.01 \leq 2.50 ; \quad \theta=44.7^{\circ}$

$\frac{A_{s w}}{s}=\frac{\pi \cdot 0.6^{2}}{2 \cdot 275}=0.206 \mathrm{~mm}^{2} / \mathrm{mm} ; f_{y w d}=\frac{500}{1.15}=435 ; \sin \alpha=1 ; \cot \alpha=0$

$V_{s u}=1.4 \frac{A_{s w}}{s} f_{y w d}\left(d_{s}-x\right) \sin \alpha(\cot \theta+\cot \alpha)=1.4 \cdot 0.206 \cdot 435 \cdot(350-54.95) \cdot 1.01$

$=37.4 \mathrm{kN}$

$V_{R d, \max }=\alpha_{c w} b_{w} z v_{1} f_{c d} \frac{\cot \theta+\cot \alpha}{1+\cot ^{2} \theta}=1 \cdot 150 \cdot 0.9 \cdot 350 \cdot 0.6 \cdot 16.67 \cdot \frac{1.01}{1+1.01^{2}}=236.3 \mathrm{kN}$

$V_{E d}=39.75 k N<V_{R d}=V_{c u}+V_{s u}=29.7+37.4=67.1<V_{R d, \max }$ 
Therefore, the shear force near the end supports is resisted. The strictly necessary area of stirrups may be computed by:

$$
\begin{gathered}
\frac{A_{s w}}{s}=\frac{V_{E d}-V_{c u}}{1.4 \cdot f_{y w d}\left(d_{s}-x\right) \sin \alpha(\cot \theta+\cot \alpha)}=\frac{39.75-29.7}{1.4 \cdot 435 \cdot(350-54.95) \cdot 1.01} \\
=0.055 \mathrm{~mm}^{2} / \mathrm{mm}
\end{gathered}
$$

The minimum amount of shear reinforcement should be provided.

6.1.2 Verification of shear strength near the central support (inverted T section, $b=b_{\underline{w}}$ )

Design shear force $V_{E d}=75.0-0.35 \cdot 15=69.75 \mathrm{kN}$

Longitudinal reinforcement area: $6 \phi 12+1 \phi 20=992 \mathrm{~mm}^{2}$

$\rho=\frac{A_{s}}{b d}=\frac{992}{150 \cdot 350}=0.0189 ; \quad \frac{x}{d}=0.75 \cdot(\alpha \cdot \rho)^{1 / 3}=0.37 ; \quad x=129.5 \mathrm{~mm}$

Note that in this case, $b$ is equal to the width of the compression chord for negative bending moment, $b_{w}$.

$b_{v}=b_{w}=b=150 \mathrm{~mm}$

Size effect: $\quad a=0.15 L=1.2 m ; \zeta=\frac{2}{\sqrt{1+\frac{350}{200}}}\left(\frac{350}{1200}\right)^{0.2}=0.94$

$V_{c u}=0.3 \zeta \frac{x}{d} f_{c d}^{\frac{2}{3}} b_{v, \text { eff }} d=0.3 \cdot 0.94 \cdot 0.37 \cdot 16.67^{\frac{2}{3}} \cdot 150 \cdot 350=35.7 k N \nless V_{c u, \text { min }}$

$V_{c u, \min }=0.25\left(\zeta k_{c}+\frac{20}{d_{0}}\right) f_{c d}^{2 / 3} b_{w} d=0.25\left(0.94 \cdot 0.2+\frac{20}{350}\right) 16.67^{\frac{2}{3}} 150 \cdot 350=21.0 \mathrm{kN}$

$\cot \theta=\frac{0.85 d_{s}}{d_{s}-x}=\frac{0.85 \cdot 350}{350-129.5}=1.35 \leq 2.50 \quad ; \quad \theta=36.5^{\circ}$

$\frac{A_{s w}}{s}=\frac{\pi \cdot 0.6^{2}}{2 \cdot 250}=0.226 \mathrm{~mm}^{2} / \mathrm{mm} ; f_{y w d}=\frac{500}{1.15}=435 ; \sin \alpha=1 ; \cot \alpha=0$

$V_{s u}=1.4 \frac{A_{s w}}{s} f_{y w d}\left(d_{s}-x\right) \sin \alpha(\cot \theta+\cot \alpha)=1.4 \cdot 0.226 \cdot 435 \cdot(350-129.5) \cdot 1.35=$ $=41.0 \mathrm{kN}$

$V_{R d, \max }=\alpha_{c w} b_{w} z v_{1} f_{c d} \frac{\cot \theta+\cot \alpha}{1+\cot ^{2} \theta}=1 \cdot 150 \cdot 0.9 \cdot 350 \cdot 0.6 \cdot 16.67 \cdot \frac{1.35}{1+1.35^{2}}=226 \mathrm{kN}$

$V_{E d}=69.75 k N<V_{R d}=V_{c u}+V_{s u}=35.7+41.0=76.7<V_{R d, \max }$ 
Therefore, the shear near the end supports is also resisted. The strictly necessary area of stirrups may be computed by:

$$
\begin{gathered}
\frac{A_{s w}}{s}=\frac{V_{E d}-V_{c u}}{1.4 f_{y w d}\left(d_{s}-x\right) \sin \alpha(\cot \theta+\cot \alpha)}=\frac{69.75-35.7}{1.4 \cdot 435 \cdot(350-129.5) \cdot 1.35 \cdot 1.348} \\
=0.139 \mathrm{~mm}^{2} / \mathrm{mm}
\end{gathered}
$$

The minimum amount of shear reinforcement should be checked.

\subsection{Post-tensioned concrete slab}

Compute the shear strength of the same slab with the same reinforcement but post-tensioned by means of a straight un-bonded tendon in each rib, placed at the center of gravity of the section $\left(A_{c}=0.112 \mathrm{~m}^{2}\right)$. The tendon consists of a $150 \mathrm{~mm}^{2}$ strand, initially stressed at $1400 \mathrm{~N} / \mathrm{mm}^{2}$, which introduces a force of $180 \mathrm{kN}$ after total losses, that can be considered constant along the whole tendon length.

The mean concrete normal stress introduced by the tendon is:

$$
\sigma_{c p}=\frac{P}{A_{c}}=\frac{180000}{112000}=1.607 \mathrm{~N} / \mathrm{mm}^{2}
$$

\subsubsection{Verification of the shear strength near the end supports}

The position and design shear force at the critical section are:

$$
s=d_{s}\left(1+0.4 \frac{\sigma_{c p}}{f_{c t m}}\right)=350\left(1+0.4 \frac{1.607}{2.56}\right)=438 \mathrm{~mm} \quad ; \quad V_{E d}=45-0.438 \cdot 15=38.4 \mathrm{kN}
$$

The neutral axis depth without prestressing is $x_{0}=54.95 \mathrm{~mm}$. Since the tendon is un-bonded it is assumed that it does not contribute to the section stiffness, but only introduces an axial force $P$ $=180 \mathrm{kN}$. Then the neutral axis depth $x$ is:

$$
x=x_{0}+0.8\left(h-x_{0}\right) \frac{d}{h} \frac{\sigma_{c p}}{\sigma_{c p}+f_{c t m}}=54.95+0.8(400-54.95) \frac{350}{400} \frac{1.607}{1.607+2.56}=148.1 \mathrm{~mm}
$$

The effective shear width is $\left(x>h_{f}\right)$ :

$$
b_{v, e f f}=b_{w}+\left(b_{v}-b_{w}\right) \cdot\left(\frac{h_{f}}{x}\right)^{2 / 3}=150+(310-150)\left(\frac{80}{148.1}\right)^{1.5}=213.5 \mathrm{~mm}
$$


Note that $b_{v}$ had been calculated in 6.1.1.

$\frac{x}{d}=\frac{148.1}{350}=0.423$

$V_{c u}=0.3 \zeta \frac{x}{d} f_{c d}^{\frac{2}{3}} b_{v, e f f} d=0.3 \cdot 0.89 \cdot 0.423 \cdot 16.67^{\frac{2}{3}} \cdot 213.5 \cdot 350=55.1 \mathrm{kN}$

Since $V_{c u}=55.1 \mathrm{kN}>V_{E d}=38.4 \mathrm{kN}$, only minimum shear reinforcement will be necessary.

6.2.2 Verification of shear strength near the central support (inverted T section, $b=b_{w}$ )

$s=d_{s}\left(1+0.4 \frac{\sigma_{c p}}{f_{c t m}}\right)=438 \mathrm{~mm} \quad ; \quad V_{E d}=45-(8-0.438) \cdot 15=-68.4 \mathrm{kN} ; \zeta=0.94$

The neutral axis depth without prestressing is $x_{0}=129.5 \mathrm{~mm}$. Since the tendon is un-bonded it is assumed that it does not contribute to the section stiffness, but only introduces an axial force $P=180 \mathrm{kN}$. Then the neutral axis depth $x$ is:

$x=x_{0}+0.8\left(h-x_{0}\right) \frac{d}{h} \frac{\sigma_{c p}}{\sigma_{c p}+f_{c t m}}=129.5+0.8(400-129.5) \frac{350}{400} \frac{1.607}{1.607+2.56}=202.5 \mathrm{~mm}$

$\frac{x}{d}=\frac{202.5}{350}=0.578$

$V_{c u}=0.3 \zeta \frac{x}{d} f_{c d}^{\frac{2}{3}} b_{v, \text { eff }} d=0.3 \cdot 0.94 \cdot 0.578 \cdot 16.67^{\frac{2}{3}} \cdot 150 \cdot 350=55.8 \mathrm{kN}$

Since $V_{c u}=55.8 \mathrm{kN}<V_{E d}=68.4 \mathrm{kN}$ shear reinforcement is necessary at central support region (probably the minimum amount). The contribution of the stirrups to the shear strength is:

$$
\begin{aligned}
& \cot \theta=\frac{0.85 d_{s}}{d_{s}-x}=\frac{0.85 .350}{350-202.5}=2.017 \leq 2.50 ; \quad \theta=26.4^{\mathrm{o}} \\
& \begin{aligned}
V_{s u}=1.4 \frac{A_{s w}}{s} f_{y w d}\left(d_{s}-x\right) \sin \alpha(\cot \theta+\cot \alpha)= \\
= \\
=1.4 \cdot 0.226 \cdot 435 \cdot(350-202.5) \cdot 2.017=40.9 \mathrm{kN}
\end{aligned}
\end{aligned}
$$

$V_{R d, \max }=\alpha_{c w} b_{w} z v_{1} f_{c d} \frac{\cot \theta+\cot \alpha}{1+\cot ^{2} \theta}=1.096 \cdot 150 \cdot 0.9 \cdot 350 \cdot 0.6 \cdot 16.67 \cdot \frac{2.017}{1+2.017^{2}}=206.1 \mathrm{kN}$

The parameter $\alpha_{\mathrm{cw}}$ has been taken equal to 1.096 . See the Notations for its definition.

$V_{E d}=68.4 k N<V_{R d}=V_{c u}+V_{s u}=55.8+40.9=96.7<V_{R d, \max }$ 
Therefore, the design shear force is resisted. The strictly necessary shear reinforcement is:

$\frac{A_{s w}}{s}=\frac{V_{E d}-V_{c u}}{1.4 f_{y w d}\left(d_{s}-x\right) \cot \theta}=\frac{68.4-55.8}{1.4 \cdot 435 \cdot(350-202.5) \cdot 2.017}=0.07 \mathrm{~mm}^{2} / \mathrm{mm}$

The minimum amount of shear reinforcement should be placed.

\section{Conclusions}

A simplified mechanical model for the shear strength of structural concrete members, named by the authors as the Compression Chord Capacity Model, based on a more general previous one already developed by the authors, has been presented and verified. The most relevant shear transfer mechanisms have been incorporated into a compact and very simple formulation, valid for direct and straightforward shear design and assessment of reinforced and prestressed concrete members, with and without transverse reinforcement, with I, T or rectangular cross section.

The model recognizes the increment of shear strength of the concrete compression chord due to the confinement provided by the stirrups, the contribution of the flanges in I or T beams through an effective shear width and the effects of the bending moment on the shear transfer capacity of the compression chord. A shear failure criteria associated to the propagation of the critical shear crack into the uncracked compression chord has been defined. In addition, a new combined size and slenderness effect factor and an expression to evaluate the neutral axis depth in prestressed and/or axially loaded members are also original contributions.

The predictions of the model fit very well the experimental results collected in the ACIDAfStb databases of shear tests on slender reinforced and prestressed concrete beams with and without stirrups. The mechanical character of the model provides valuable information about the physics of the problem and incorporates the most relevant parameters governing the shear strength of structural concrete members. Due to this fact and the simplicity of the derived equations it may become a very useful tool for structural design and assessment in engineering practice. 


\section{Acknowledgments}

The present work has been developed under the framework of research projects BIA2012-31432 and BIA2012-36848, funded by the Spanish Ministry of Economy and Competitiveness (MINECO) and the Europeans Funds for Regional Development (ERDF). The authors also want to acknowledge the support provided by Infraestructures of Catalonia (ICAT) and by many practising engineers and researchers who disinterestedly provided helpful feedback to make the proposal simpler to use.

\section{Notation}

a shear span, equal to $M_{E d, \max } / V_{E d, \max }$, where $M_{E d, \max }$ and $V_{E d, \max }$ are the maximum absolute values of the internal forces in the region between the maximum bending moment and the zero bending moment in which the considered section is located. This is equivalent to the distance from the support to the resultant of the loads producing shear at that support. For design, in members with uniformly distributed load, $a=0.25 L$ for simple supported members; $a=0.5 \mathrm{~L}$ in the case of a cantilever beam; $a=0.2 \mathrm{~L}$ for the sagging moment regions in continuous members and $a=0.15 L$ for the hogging moment regions in continuous members, being $L$ the span of the member or the length of the cantilever.

b width of the cross-section. For T or I-shaped is equal to the flexural effective compression flange width

$b_{v, \text { eff }}$ effective width for shear strength calculation. For rectangular beams, $b_{v, e f f}=b$. For T or I beams with compression flange, it may be computed by means of Eq. (9) for the general model (multi-action model). For the simplify model, use Eq. (17). For L beams with one compression flange, the value $2 h_{f}$ of Eq. (9a) and (17a) shall be substituted by $h_{f}$.

$b_{w} \quad$ width of the web on T, I or L beams. For rectangular beams $b_{w}=b$

$d \quad$ effective depth of the cross-section. For members containing mild steel reinforcement and prestressed tendons, $d=\frac{A_{S} d_{S}+A_{p} d_{p}}{A_{S}+A_{p}}$ 
$d_{0} \quad$ effective depth of the cross-section, $d$, but not less than $100 \mathrm{~mm}$

$d_{\max }$ maximum aggregate size

$d_{s} \quad$ distance between the maximum compressed concrete fibre and the centroid of the mild steel tensile reinforcement. In the case of prestressed elements without mild reinforcement, $d_{s}$ shall be taken equal to $d_{p}$

$d_{p} \quad$ distance between the maximum compressed concrete fibre and the mechanical centroid of the prestressing tendons placed at the tension zone

$f_{c d} \quad$ is the design value of concrete compressive strength

$f_{c k} \quad$ characteristic compressive strength of concrete

$f_{c m} \quad$ mean compressive strength of concrete

$f_{c t m}$ mean tensile strength of concrete, in MPa, not greater than 4.60

$f_{y w d} \quad$ design yield strength of the shear reinforcement

$h \quad$ overall depth of a cross-section

$h_{f}$ height of the compression flange. In T, I or L beams with haunches, $h_{f}$ can be considered the flange height plus half the haunch

$s \quad$ longitudinal coordinate from the support

$S_{c r} \quad$ location of the section where the critical shear crack starts

$s_{t} \quad$ spacing of the stirrups neutral axis depth of the cracked section, obtained assuming zero concrete tensile strength

$x_{0} \quad$ neutral axis depth of a $\mathrm{RC}$ member or of a PC member considering $\mathrm{P}=0$ and the same amounts of reinforcements

$y_{t} \quad$ distance from the concrete section centroid to the most tensioned fibre under the external bending moment

$z \quad$ inner lever arm, for a member with constant depth, corresponding to the bending moment in the element under consideration. In the shear analysis of reinforced concrete members without axial force, the approximate value $z \approx 0.9 d$ may normally be used

$A_{c} \quad$ cross sectional area of concrete

$A_{p} \quad$ cross sectional area of prestressing steel 
$\mathrm{A}_{s} \quad$ cross sectional area of mild reinforcement

$A_{s w} \quad$ cross-sectional area of the shear reinforcement

$E_{c m}$ secant modulus of elasticity of concrete, $E_{c m}=22000\left(f_{c m} / 10\right)^{0.3} \ngtr 39 \mathrm{GPa}$

$E_{s} \quad$ modulus of elasticity of reinforcing steel

$F_{\text {td }} \quad$ design value of the tensile force in the longitudinal reinforcement

$F_{\text {cd }} \quad$ design value of the concrete compression force in the direction of the longitudinal member axis

$G_{f} \quad$ concrete fracture energy, $G_{f}=0.028 f_{c m}^{0.18} d_{\max }^{0.32}$

$K_{c} \quad$ is equal to the relative neutral axis depth, $x / d$, but not greater than 0.20

$K_{p} \quad$ strength factor which takes into account the effects of the axial load, including prestressing, (compression positive), and the interaction with the bending moment acting at the considered section. See Eq. (10) for its definition in the mechanical model. This factor is taken equal to 1.0 in the simplified model.

$M_{c r}$ cracking moment at the section where shear strength is checked calculated using the mechanical properties of the gross concrete section and the flexural tensile strength

$M_{E d}$ concomitant design bending moment, considered positive

$N_{E d} \quad$ concomitant design axial or prestressing force (compression positive)

$P \quad$ prestressing tendon force after total losses

$V_{E d} \quad$ design shear force in the section considered

$V_{E d, 0}$ design shear force in the section considered due only to the external loading

$V_{R d} \quad$ design shear resistance of the member

$V_{R d, \max }$ design value of the maximum shear force which can be sustained by the member, limited by crushing of the struts

$V_{u} \quad$ shear resistance of the member calculated by the background mechanical model

$V_{u, \max }$ maximum shear force which can be sustained by the member, limited by crushing of the struts in the background mechanical model or multi-action model.

$\alpha \quad$ angle between shear reinforcement and the beam axis perpendicular to the shear force (measured positive as shown in Figure 8) 
$\alpha_{\mathrm{cw}}$ coefficient taking account the state of the stress in the struts: $\alpha_{c w}=1$ for non prestressed structures; $\alpha_{c w}=1+\sigma_{c p} / f_{c d}$ for $0 \leq \sigma_{c p} \leq 0.25 f_{c d} ; \alpha_{c w}=1.25$ for $0.25 f_{c d}<\sigma_{c p} \leq$ $0.50 f_{c d} ;$ and $\alpha_{c w}=2.5\left(1-\sigma_{c p} / f_{c d}\right)$ for $0.50 f_{c d}<\sigma_{c p} \leq f_{c d}$

$\alpha_{e} \quad$ modular ratio, $\alpha_{e}=E_{s} / E_{c m}$

$\delta_{p} \quad$ angle between the prestressed tendon axis and the beam axis perpendicular to the shear force (Figure 8)

$v_{1} \quad$ strength reduction factor for concrete cracked in shear, $v_{1}=0.6$ for $f_{c k} \leq 60 \mathrm{MPa}$ and $v_{1}=$ $0.9-f_{c k} / 200$ for $f_{c k}>60 \mathrm{MPa}$

$\theta \quad$ angle between the concrete compression strut and the beam axis perpendicular to the shear force

$\rho_{l} \quad$ longitudinal tensile reinforcement ratio referred to the effective depth $d$ and the width $b$. For members with mild steel reinforcement and tendons, $\alpha_{e} \rho_{l}$ can be adopted as $\alpha_{e} \rho_{l}=\alpha_{e, s} \rho_{s}+\alpha_{e, p} \rho_{p}$ being $\alpha_{e, s}=E_{s} / E_{c m}, \alpha_{e, p}=E_{p} / E_{c m}, \rho_{s}=A_{s} / b d, \rho_{p}=$ $A_{p} / b d$ and $b$ the width of the cross-section according to Figure 8. For the case of unbonded tendons, $A_{p}=0$.

$\sigma_{c p} \quad$ concrete compressive stress at the centroidal axis due to axial loading and/or prestressing $\left(\sigma_{c p}=N_{E d} / A_{c}\right.$ in $\mathrm{MPa}, N_{E d}>0$ in compression $)$

$\zeta \quad$ size effect coefficient, given by Eq. (11) for the background mechanical model and Eq. (20) for the model presented in this paper (combined size and slenderness effect factor).

$\Delta_{V c u}$ non-dimensional confinement factor which considers the increment of the shear resisted by the concrete caused by the stirrup confinement in the compression chord, see Eq. (14). This factor is taken equal to 0.4 in the simplified model.

$\Delta F_{t, d}$ additional tensile force in the longitudinal reinforcement due to the shear force $V_{E d}$ 


\section{Appendixes}

\section{A1. Derivation of compact expression for $V_{c u}$}

To derive the compact expression, $v_{w}(\mathrm{Eq} 4)$ and $v_{l}$ (Eq. 5) have been incorporated into $v_{c}$ (Eq. 3) taking into account that when shear-flexure failure takes place, both the residual tensile stresses and the dowel action are small compared to the shear resisted by the uncracked zone. For this purpose, average values $v_{w}=0.035$ and $v_{l}=0.025$ have been considered. On one hand, the term $v_{w}$ has been added to the constant 0.02 in Eq. (3) and both terms have been included in the term multiplying $x / d$, considering $x / d=0.35$. On the other, the action term $v_{l}$, which only exists when $A_{s t}>0$, has been added to the factor multiplying $v_{s}$ in Eq. (3), considering a value of $v_{s}=0.25$. The tensile strength $f_{c t m}$ has been considered equal to $0.30 \cdot f_{c k}^{2 / 3}$. The detailed derivation is as follows:

$$
\begin{aligned}
& V_{u}=\left(v_{c}+v_{w}+v_{l}\right) f_{c t m} \cdot b \cdot d+V_{s}= \\
& =\left(\zeta\left[\left(0.88+\left(0.20+0.50 \frac{b}{b_{w}}\right) v_{s}\right) \frac{x}{d}+0.02\right] \frac{b_{v, e f f}}{b} K_{p}+v_{w}+v_{l}\right) f_{c t m} \cdot b \cdot d+V_{s}= \\
& =\left(\zeta\left[\left(0.88+\left(0.20+0.50 \frac{b}{b_{w}}\right) v_{s}\right) \frac{x}{d}+0.02\right] \frac{b_{v, e f f}}{b} K_{p}+0.035+0.025\right) f_{c t m} \cdot b \cdot d+V_{s}= \\
& =\left(\zeta\left[\left(0.88+\frac{0.02}{0.35}+\frac{0.035}{0.35}+\left(0.20+\frac{0.025}{0.35 \cdot 0.25}+0.50 \frac{b}{b_{w}}\right) v_{s}\right) \frac{x}{d}\right] \frac{b_{v, e f f}}{b} K_{p}\right) f_{c t m} \cdot b \cdot d+V_{s}= \\
& =\left(\zeta\left[\left(1.04+\left(0.49+0.50 \frac{b}{b_{w}}\right) v_{s}\right) \frac{x}{d}\right] \frac{b_{v, e f f}}{b} K_{p}\right) f_{c t m} \cdot b \cdot d+V_{s} \approx \\
& \approx 0.30 \zeta f_{c k}^{2 / 3} \frac{x}{d} K_{p} b_{v, e f f} d+0.5 \zeta\left(1+\frac{b}{b_{w}}\right) \frac{x}{d} \frac{b_{v, e f f}}{b} K_{p} \frac{V_{s}}{b \cdot d \cdot f_{c t}} f_{c t m} \cdot b \cdot d+V_{s}= \\
& =0.30 \zeta f_{c k}^{2 / 3} \frac{x}{d} b_{v, e f f} d+V_{s}\left[1+0.5 \zeta\left(1+\frac{b}{b_{w}}\right) \frac{x}{d} \frac{b_{v, e f f}}{b}\right]=0.30 \zeta \frac{x}{d} f_{c k}^{2 / 3} b_{v, e f f} d+V_{s}\left[1+\Delta_{V c u}\right]= \\
& =V_{c u}+V_{s}\left[1+\Delta_{V c u}\right]
\end{aligned}
$$

It is recommended to adopt a constant value, $\Delta_{V c u}=0.4$, for the non-dimensional confinement factor to simplify the calculation procedure.

In the background mechanical model, $K_{p}$ is a strength factor which takes into account the effects of the axial load, including prestressing (compression positive), and it can be simplified as:

$$
K_{p}=1+0.24 \frac{P \cdot y_{t}}{f_{c t m} b d^{2}}
$$

where $y_{t}$ is the distance from the centroid of the section to the most stressed fibre in tension, and it is a simplification of the term $x+d_{s}-d_{p}$ (parenthesis in the right in Eq. 10). In the previous equation a coefficient $0.30 \cdot 0.8=0.24$ has been used in spite of the original value of 0.30 , to 
take into account that the neutral axis depth in prestressed concrete sections (see Eq. 8) is higher than the one assumed to merge the different components into a single concrete contribution $V_{c}$ and due to the fact that the load $P$, which is a favourable action, is not minored in the structural codes. However, $K_{p}$ has been considered equal to 1.0 due to the relatively low influence of this parameter and for simplicity reason in the code-type expression.

\section{A2. Derivation of $V_{c u, \min }$}

A simplified equation for a minimum value for the shear strength is derived. Average values for a $25 \mathrm{MPa}$ compressive strength concrete have been assumed:

$$
\begin{aligned}
& V_{c u, \min }=\left(v_{c}+v_{w}\right) f_{c t m} \cdot b \cdot d= \\
& =\left(\zeta\left[0.88 \frac{x}{d}+0.02\right] \frac{b_{v, e f f}}{b} K_{p}+167 \frac{f_{c t m}}{E_{c}}\left(1+\frac{2 \cdot G_{f} \cdot E_{c}}{f_{c t m}^{2} \cdot d_{0}}\right) \frac{b_{w}}{b}\right) f_{c t m} \cdot b \cdot d= \\
& =\left(\zeta\left[0.88 \frac{x}{d}+0.02\right] \frac{b_{v, e f f}}{b} \cdot 1+0.015\left(1+\frac{1206}{d_{0}}\right) \frac{b_{w}}{b}\right) f_{c t m} \cdot b \cdot d \approx \\
& \approx\left(\zeta \frac{x}{d} 0.88 b_{v, e f f}+0.015 b_{w}+\frac{18.1}{d_{0}} b_{w}\right) 0.30 f_{c k}^{2 / 3} d \approx\left(\zeta \frac{x}{d} 0.264+0.0045+\frac{5.43}{d_{0}}\right) f_{c k}^{2 / 3} \cdot b_{w} d= \\
& \approx 0.25\left(\zeta \frac{x}{d}+\frac{20}{d_{0}}\right) f_{c k}^{2 / 3} \cdot b_{w} d
\end{aligned}
$$

The previous equation is intended for the particular cases in which the residual stresses across the crack are relatively important compared to the stresses transferred by the concrete compression chord. For this reason, it is recommended to limit $x / d$ to values lower to 0.20 for application of this $V_{c u, m i n}$ expression.

\section{A3. Position of the critical shear crack and the critical section}

One of the assumptions of the model is that the critical crack starts where the bending moment diagram at failure reaches the cracking moment of the section. Then, the distance from the zero bending moment point to the initiation of the critical shear crack, $s_{c r}$, is $s_{c r}=M_{c r} / V_{u} \geq s_{\min }$, where $\mathrm{S}_{\min }$ is the crack spacing, i.e. the necessary distance to transfer tensile stresses from the reinforcement to the concrete so that another crack is formed. The control section would be placed at a distance from the zero bending moment point $s_{c r}+0.85 \mathrm{~d}$. 
For rectangular sections, with $h=1.1 d$, the cracking moment, adopting $f_{c t d}$ in in ULS, is $M_{c r} \cong 0.2 f_{c t d} \cdot b d$. Taking into account that $V_{u}=V_{c u}+V_{s u}$ and adopting for $V_{c u}$ and $V_{s u}$ the values provided by the model in the design format, Eqs. (25) to (28), the following expression is obtained for the position where the critical crack starts:

$$
s_{c r}=\frac{M_{c r}}{V_{u}}=\frac{0.2 d}{1.63 \zeta \frac{x}{d}+1.2 \rho_{w} \frac{f_{y w d}}{f_{c t, d}}} \geq s_{\min }
$$

where it has been taken into account that:

$$
0.3 f_{c d}^{2 / 3}=0.3\left(\frac{f_{c k}}{1.5}\right)^{2 / 3}=0.763 \cdot 0.3 f_{c k}^{2 / 3}=0.763 f_{c t, m}=1.63 f_{c t, d}
$$

It can be seen that the higher are the longitudinal or shear reinforcement ratios the closer is the crack to the zero bending moment point. Similarly, in beams without stirrups the critical crack is farther from the zero bending moment point than in beams with stirrups.

To use the above expression in design is not practical nor possible since the shear reinforcement ratio is not known a priori. Therefore, a constant and conservative value is considered convenient to be adopted for design purposes. Considering usual ranges of the parameters involved in the equation for $s_{c r}$ derived in this appendix, ( $\zeta$ between 0.7 and $1.0, \rho_{l}$ between 0.005 and $0.02, \rho_{w}$ between 0 and $0.3 \%$ ) and assuming $f_{y w d}=435 \mathrm{MPa}$, and $f_{c t, d}=1.4$ $\mathrm{MPa})$ the position of the critical section $s_{c r}+0.85 d$ ranges between $0.97 \cdot d$ and $1.6 \cdot d$. Therefore, for design purposes a conservative value, $d$, is adopted.

For PC beams, even though the neutral axis increases, the increment of the cracking moment is higher, and the control section shall be shifted away from the zero bending moment point. The simplification made by the authors in the paper, drives to expression $d_{s}\left(1+0.4 \sigma_{c p} / f_{c t m}\right)$, which is a conservative approach, as the shear force increases towards the support.

\section{A4. Additional tensile force in the longitudinal reinforcement}


The additional tensile force, $\Delta F_{\mathrm{td}}$, in the longitudinal reinforcement due to the shear force $V_{\mathrm{Ed}}$ is given by Eq. (29). This equation is derived from the free body diagram shown in Fig. A41.b. The free body diagram for the multi-action background model is shown in Fig. A4.1.a and for the simplified Compression Chord Capacity Model is shown in Fig. A4.1.b. In the last, it has been assumed that the application point of the action $V_{s u}$ (Eq. 27) remains in the same point that the resultant force caused only by the stirrups, $V_{s}$ in Fig. A4.1.a. Note that $V_{s u}$ (Eq. 27) includes the dowel effect, $V_{l}$, and the confinement effect in the compression chord, $\Delta_{V c u} \cdot V_{s}$, as derived in Appendix A1. The term $V_{c u}$ (Eq. 26) in Fig. A4.1.b takes into account the stresses transferred in the compression chord, $V_{c}$, and the residual tensile stresses near the tip of the crack, $V_{w}$, shown in Fig. A4.1.a for the multi-action model. Applying equilibrium equations in the free body diagram shown in Fig. A41.b, the following expression for the force in the longitudinal reinforcement is obtained:

$$
F_{t d}=\frac{M_{E d}}{Z}+V_{E d} \cot \theta-0.5 V_{s u}(\cot \theta+\cot \alpha)
$$

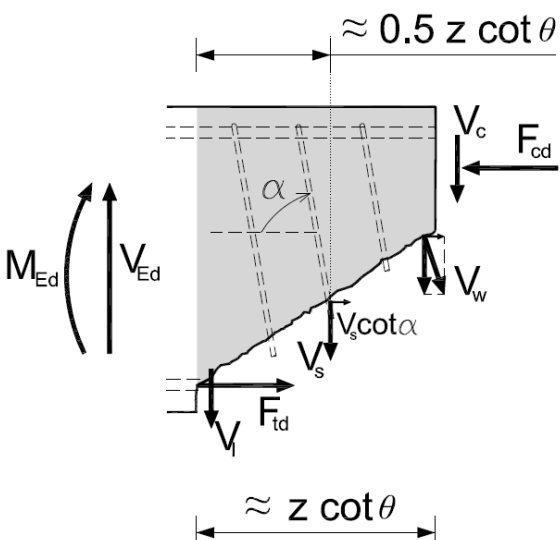

a)

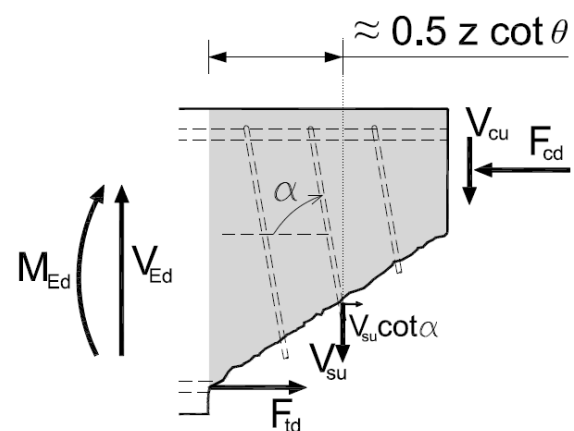

$\approx \mathrm{z} \cot \theta$

Fig. A4.1. Free body diagram for the determination of the additional force in the longitudinal reinforcement. A) Multi-action model. B) Compression Chord Capacity Model.

\section{References}

1. Golder, H.Q.: Coulomb and earth pressure. Géotechnique,1948, 1, 66-71.

2. Kani, G.N.J.: The Riddle of Shear Failure and its Solution. J Am Concr Inst, 1964, 61, $441-468$.

3. Regan P.E.: Research on shear: a benefit to humanity or a waste of time? Struct Eng, 
1993, 71-337.

4. European Committee for Standardization. Eurocode 2: Design of Concrete Structures: Part 1: General Rules and Rules for Buildings. 2002.

5. ACI-Committee-318. Building Code Requirements of Structural Concrete and Commentary. 2011. ACI.

6. Siess C.P.: Research, building codes, and engineering practice. J Am Concr Inst, 1960, $56,1105-1122$.

7. Bairán, J.M. and Marí, A.R.: Coupled model for the non-linear analysis of anisotropic sections subjected to general 3D loading. Part 1: Theoretical formulation. Comput Struct, $2006,84,2254-2263$.

8. Bentz, E.C.: Sectional analysis of reinforced concrete members. PhD Thesis, University of Toronto, 2000.

9. Ferreira, D., Bairán, J. and Marí, A.: Numerical simulation of shear-strengthened RC beams. Eng Struct, 2013, 46, 359-374.

10. Navarro-Gregori, J., Miguel-Sosa, P., Fernández-Prada, M.A. and Filippou, F.C.: A 3D numerical model for reinforced and prestressed concrete elements subjected to combined axial, bending, shear and torsion loading. Eng Struct, 2007, 29, 3404-3419.

11. Petrangeli, M., Pinto, P.E. and Ciampi, V.: Fiber element for cyclic bending and shear of RC structures. I: Theory. J Eng Mech, 1999, 125, 994-1001.

12. Saritas, A. and Filippou, F.C.: Inelastic axial-flexure-shear coupling in a mixed formulation beam finite element. Int J Non Linear Mech, 2009, 44, 913-922.

13. Vecchio, F.J. and Collins, M.P.: The modified compression-field theory for reinforced concrete elements subjected to shear. ACI J, 1986, 83, 219-231.

14. Vecchio, F.J.: Disturbed stress field model for reinforced concrete: formulation. J Struct Eng, 2000, 126, 1070-1077.

15. Nielsen, M.P., Braestrup, M.W. and Bach, F.: Rational analysis of shear in reinforced concrete beams. In: IABSE proceedings, 1978, 15, pp 1-16.

16. Choi K.K. and Hong-Gun, P.: Unified Shear Strength Model for Reinforced Concrete 
Beams-Part II: Verification and Simplified Method. ACI Struct J, 2007, 104, 153-166.

17. Collins, M.P., Bentz, E.C., Sherwood, E.G. and Xie, L.: An adequate theory for the shear strength of reinforced concrete structures. Mag Concr Res, 2008, 60, 635-650.

18. Muttoni, A. and Fernández-Ruiz, M.: Shear strength of members without transverse reinforcement as function of critical shear crack width. ACI Struct J, 2008, 105, 163-172

19. Colajanni, P., Recupero, A. and Spinella, N.: Generalization of shear truss model to the case of SFRC beams with stirrups. Comput Concr, 2012, 9, 227-244.

20. Reineck, K.H.: Ultimate shear force of structural concrete members without transverse reinforcement derived from a mechanical model. ACI Struct J, 1991, 88, 592-602.

21. Wolf, T.S. and Frosch, R.J. Shear design of prestressed concrete: A unified approach. J Struct Eng, 2007, 133, 1512-1519.

22. Zararis, P.D. and Papadakis, G.C.: Diagonal shear failure and size effect in RC beams without web reinforcement. J Struct Eng, 2001, 127, 733-742.

23. Marí, A., Bairán, J., Cladera, A., Oller, E. and Ribas, C.: Shear-flexural strength mechanical model for the design and assessment of reinforced concrete beams. Struct Infrastruct Eng, 2015, 11, 1399-1419.

24. Cladera, A., Marí, A., Ribas, C., Bairán, J. and Oller, E.: Predicting the shear-flexural strength of slender reinforced concrete T and I shaped beams. Eng Struct, 2015, 101, $386-398$.

25. Marí, A., Bairán, J.M., Cladera, A. and Oller, E.: Shear design and assessment of reinforced and prestressed concrete beams based on a mechanical model. J. Struct. Eng., 2016, Accepted for publication. DOI: 10.1061/(ASCE)ST.1943-541X.0001539

26. Reineck, K.H., Bentz, E.C., Fitik, B., Kuchma, D.A. and Bayrak, O.: ACI-DAfStb database of shear tests on slender reinforced concrete beams without stirrups. ACI Struct J, 2013, 110, 867-875.

27. Reineck, K.H., Bentz, E., Fitik, B., Kuchma, D.A. and Bayrak, O.: ACI-DAfStb Databases for Shear Tests on Slender Reinforced Concrete Beams with Stirrups. ACI Struct J, 2014, 111, 1147-1156. 
28. ACI-DAfStb 617: ACI-DAfStb databases 2015 on shear tests for evaluating relationships for the shear design of structural concrete members without and with stirrups. Beuth Verl, Berlin, 2015.

29. Marí, A., Cladera, A., Oller, E. and Bairán, J.: Shear design of FRP reinforced concrete beams without transverse reinforcement. Compos Part B Eng, 2014, 57, 228-241.

30. Oller, E., Marí, A., Bairán, J.M. and Cladera, A.: Shear design of reinforced concrete beams with FRP longitudinal and transverse reinforcement. Compos Part B Eng, 2015, $74,104-122$.

31. Kupfer, H.B. and Gerstle, K.H.: Behavior of concrete under biaxial stresses. J Eng Mech Div, 1973, 99, 853-866.

32. Fédération Internationale du Béton: fib Model Code for Concrete Structures 2010. Ernst \& Sohn, 2013.

33. Sigrist, V.: Generalized Stress Field Approach for Analysis of Beams in Shear. Struct J, $2011,108,479-487$.

34. Yu, Q., Le. J.L., Hubler, M.H., Wendner, R., Cusatis, G. and Bažant, Z.P.: Comparison of Main Models for Size Effect on Shear Strength of Reinforced and Prestressed Concrete Beams, Northwester University, Structural Engineering Report No. 1503/936x, 2015, 29 pp.

35. Choulli, Y., Marí, A.R. and Cladera, A.: Shear behaviour of full-scale prestressed Ibeams made with self compacting concrete. Mater Struct Constr, 2008, 41, 131-141.

36. Choulli, Y.: Shear Behavior of Prestressed I-Beams made with High-Strength Self Compacting Concrete. PhD Thesis, Universitat Politècnica de Catalunya, 2005.

37. Elzanaty, A.H., Nilson, A.H. and Slate, F.O.: Shear Capacity of Prestressed Concrete Beams Using High-Strength Concrete. ACI J 1986, 83, 359-368.

38. Hasegawa, T., Shioya, T. and Okada, T.: Size effect on splitting tensile strength of concrete. In Proceedings 7th JCI Conf. Japan Concr. Inst., Tokyo, 1985, 309-312.

39. Bažant, Z.P., Hasegawa, M.T. and Mazars, J.: Size Effect in Brazilian Split-Cylinder Tests: Measurements and Fracture Analysis. Mater J, 1991, 88, 325-332. 
40. Kani, M.W., Huggins, M.W. and Wittkopp, R.R.: Kani on shear in reinforced concrete. Dept. of Civil Engineering, University of Toronto, 1979.

41. Leonhardt, F. and Walther R.: Schubversuche an Einfeldrigen Stahlbeton-Balken mit und ohne Schubbewehrung zur Ermittlung der Schubtragfhigkeit und der Oberen Schubspannungsgrenze. H 151, Deutcher Ausschuss Fr Stahlbet 66, 1962.

42. Collins, M.P., Bentz, E.C. and Sherwood, E.G.: Where is shear reinforcement required? Review of research results and design procedures. ACI Struct J, 2008, 105, 590-600.

43. Bažant, Z.P., Yu, Q., Gerstle, W., Hanson, J. and Ju, J.W.: Justification of ACI 446 Proposal for Updating ACI Code Provisions for Shear Design of Reinforced Concrete Beams. ACI Struct J, 2007, 104, 601-610.

44. Pérez, J.L., Cladera, A., Rabuñal, J.R. and Martínez-Abella, F.: Optimization of existing equations using a new Genetic Programming algorithm: Application to the shear strength of reinforced concrete beams. Adv Eng Softw, 2012, 50, 82-96.

45. Cladera, A., Pérez-Ordóñez, J.L. and Martínez-Abella, F.: Shear strength of RC beams. Precision, accuracy, safety and simplicity using genetic programming. Comput Concr, 2014, 14, 479-501.

46. Sangiorgio, F., Silfwerbrand, J. and Mancini, G.: Scatter in the shear capacity of slender RC members without web reinforcement: an overview study. Struct Concr, 2016, 17, $11-20$.

47. Herbrand, M. and Classen, M.: Shear tests on continuous prestressed concrete beams with external prestressing. Struct Concr 2015, 16, 428-437.

48. Severcan, M.H.: Prediction of splitting tensile strength from the compressive strength of concrete using GEP. Neural Comput Appl 2012, 21, 1937-1945.

49. Walraven, J.C. The influence of depth on the shear strength of lightweight concrete beams without shear reinforcement. Stevin Lab Report S-7, Delft Univiversty, 1978.

50. Bhal, N.S.: Uber den Einfluss der Balkenhöhe auf Schubtragfähigkeit von einfeldrigen Stahlbetonbalken mit und ohne Schubbewehrung. PhD Thesis, 1968.

51. Zararis, P.D. and Papadakis, G.: Influence of the arrangement of reinforcement on the 
shear strength of RC beams. Proc 13th Hell Conf Concr, 1999, 1, 110-119.

52. Roller, J.J. and Russell, H.G.: Shear strength of high-strength concrete beams with web reinforcement. ACI Struct J, 1990, 87, 191-198.

53. Sato, T., Ishibashi, T., Yamashita, Y. and Takada, S.: Shear Strength and Failure Mode of Prestressed Concrete Beams (in Japanese). Trans Japan Concr Inst, 1987, 9, 323-328.

54. Saqan, E.I. and Frosch, R.J.: Influence of Flexural Reinforcement on Shear Strength of Prestressed Concrete Beams. ACI Struct J, 2009, 106, 60-68.

55. Moayer, M. and Regan, P.E.: Shear Strength of Prestressed and Reinforced Concrete TBeams. ACI Spec Publ 42, 1974, 183-214.

56. Hanson, J.M. and Hulsbos, C.L.: Ultimate shear tests of prestressed concrete I-beams under concentrated and uniform loadings. PCI J, 1964, 9, 15-28. 


\section{Table captions}

Table 1. Summary of dimensionless shear contributing components and factors considered in the mechanical model for members cracked in bending.

Table 2. Verification of the proposed model for different databases: mean value and Coefficient of Variation (\%) for $V_{\text {tes }} / V_{\text {pred }}$ ratio.

Table 3. Comparison of the $V_{\text {tes }} / V_{\text {pred }}$ ratio for the proposed model and EC-2 equations using $f_{c m}$, $f_{c k}$ and materials safety partial coefficients $\gamma_{c}=1.5$ and $\gamma_{s}=1.15$. 


\section{Figure captions}

Fig. 1. Critical shear crack evolution and horizontal projection of the first branch of this crack.

Fig. 2. Adopted failure envelope for concrete under a biaxial stress state. Adapted from [31].

Fig. 3. Shear contributing actions at failure. a) Background mechanical model for elements without stirrups. b) Background mechanical model for elements with stirrups. c) Model Code 2010 model. d) Variable angle truss model.

Fig. 4. Crack pattern at failure in a prestressed concrete girder without flexural cracks $[35,36]$.

Fig. 5. Exact value of the neutral axis depth ratio and simplified expression given in Eq. (15).

Fig. 6. Comparison between exact and simplified relative effective width for shear strength calculations.

Fig. 7. Comparison between size effect term given by Eq. (11) and new size effect term given by Eq. (20).

Fig. 8. Shear contributions and notation for simple supported beam and cantilever beam.

Fig. 9. Correlation between the predictions and the experimental results as a function of the effective depth, $d$, for the 1285 beams included in the four ACI-DafStb databases.

Fig. 10. Correlation between the prediction and experimental results for RC beams: A) Size effect in beams w/o stirrups [49]. B) Size effect in beam w/o stirrups [50]. C) Influence of the stirrup index [51]. D) Influence of the stirrup index [52].

Fig. 11. Correlation between the prediction and experimental results for PC beams: A) Influence of prestressing ratio $\sigma_{c p} / f_{c t m}$ in beams w/o stirrups [53]. B) Influence of amount of prestressing reinforcement for constant prestressing force in beams w/o stirrups [54]. C) Influence of prestressing ratio $\sigma_{c p} / f_{c t m}$ in beams with stirrups [55]. D) Influence of the stirrup index [56].

Fig. 12. Dimensions and reinforcement layouts.

Fig. 13. Design bending moments and shear forces distributions $\left(\gamma_{G}=1.35, \gamma_{Q}=1.50\right)$.

Fig. A4.1. Free body diagram for the determination of the additional force in the longitudinal reinforcement. A) Multi-action model. B) Compression Chord Capacity Model. 
Table 1. Summary of dimensionless shear contributing components and factors considered in the mechanical model for members cracked in bending.

\begin{tabular}{|c|c|c|c|}
\hline Contributing component & Dimensionless expressions & & \\
\hline Compression chord & $v_{c}=\zeta\left\{\left(0.88+\left(0.20+0.50 \frac{b}{b_{w}}\right) v_{s}\right) \frac{x}{d}+0.02\right.$ & $\frac{b_{v, e f f}}{b} K_{p}$ & (3) \\
\hline Cracked concrete web & $v_{w}=167 \frac{f_{c t m}}{E_{c m}} \frac{b_{w}}{b}\left(1+\frac{2 \cdot G_{f} \cdot E_{c m}}{f_{c t m}^{2} \cdot d_{0}}\right)$ & & (4) \\
\hline Longitudinal reinforcement & $\begin{array}{l}\text { if } v_{s}>0 \rightarrow v_{l}=0.23 \frac{\alpha_{e} \cdot \rho_{l}}{1-x / d} \\
\text { if } v_{s}=0 \rightarrow v_{l}=0\end{array}$ & & $\begin{array}{l}(5 a) \\
(5 b)\end{array}$ \\
\hline Transversal reinforcement & $v_{s}=\left(d_{s}-x\right) \cot \theta \frac{A_{s w} \cdot f_{y w}}{s \cdot f_{c t m} \cdot b \cdot d} \approx \frac{0.85 d_{s} A_{s w} \cdot f_{y w}}{s \cdot f_{c t m} \cdot b \cdot d}$ & & (6) \\
\hline Factors & Expressions & & \\
\hline Neutral axis depth ratio for $\mathrm{RC}$ beam & $\frac{x_{0}}{d}=\alpha_{e} \rho_{l}\left(-1+\sqrt{1+\frac{2}{\alpha_{e} \rho_{l}}}\right)$ & & (7) \\
\hline Neutral axis depth ratio for PC beam & $\frac{x}{d}=\frac{x_{0}}{d}+\left(\frac{h-x_{0}}{d}\right)\left(\frac{d}{h}\right) \frac{\sigma_{c p}}{\sigma_{c p}+f_{c t m}}$ & & (8) \\
\hline & if $x \leq h_{f} \quad \rightarrow \quad b_{v, e f f}=b_{v}=b_{w}+2 h_{f} \leq b$ & & (9a) \\
\hline Effective width & if $x>h_{f} \rightarrow b_{v, e f f}=b_{v} \eta+b_{w}(1-\eta) \quad ; \quad \eta=3\left(\frac{h_{f}}{x}\right)^{2}$ & $-2\left(\frac{h_{f}}{x}\right)^{3}$ & (9b) \\
\hline Strength factor related to $M_{c r}$ & $K_{p}=1+0.3 \frac{P \cos \alpha\left(x+d_{s}-d_{p}\right)}{f_{c t m} b d^{2}}$ & & (10) \\
\hline Size effect in compression chord & $\zeta=1.2-0.2 a \geq 0.65 \quad(a$ in meters $)$ & & (11) \\
\hline Critical crack inclination & $\cot \theta=\frac{0.85 d_{s}}{\left(d_{s}-x\right)} \leq 2.5$ & & (12) \\
\hline
\end{tabular}


Table 2. Verification of the proposed model for different databases: mean value and Coefficient of Variation (\%) for $V_{\text {test }} / V_{\text {pred }}$ ratio.

\begin{tabular}{|c|c|c|c|c|c|c|c|c|c|c|c|}
\hline \multirow{2}{*}{$\begin{array}{l}\text { Database } \\
\text { original source }\end{array}$} & \multirow{2}{*}{$\begin{array}{l}\text { No. } \\
\text { beams }\end{array}$} & \multicolumn{2}{|c|}{$\begin{array}{c}\text { Code format } \\
\text { proposal } \\
\text { (Section 4) }\end{array}$} & \multicolumn{2}{|c|}{ ACl318-11 } & \multicolumn{2}{|c|}{ EC-2 } & \multicolumn{2}{|c|}{ MC-2010 } & \multicolumn{2}{|c|}{ CSA A23.3-14 } \\
\hline & & Mean & CoV & Mean & CoV & Mean & CoV & Mean & CoV & Mean & CoV \\
\hline RC beams w/o stirrups [25] & 784 & 1.17 & 18.5 & 1.42 & 38.3 & 1.10 & 27.9 & 1.22 & 22.8 & 1.22 & 22.3 \\
\hline $\mathrm{RC}$ beams with stirrups [26] & 170 & 1.16 & 14.1 & 1.53 & 25.2 & 1.47 & 26.4 & 1.28 & 17.2 & 1.29 & 17.3 \\
\hline PC beams w/o stirrups [27] & 214 & 1.21 & 22.1 & 1.52 & 35.1 & 1.56 & 29.8 & 1.85 & 33.9 & 1.68 & 29.8 \\
\hline PC beams with stirrups [27] & 117 & 1.18 & 16.5 & 1.28 & 20.5 & 1.54 & 37.2 & 1.38 & 19.6 & 1.40 & 16.2 \\
\hline All & 1285 & 1.17 & 18.6 & 1.44 & 35.3 & 1.26 & 34.1 & 1.35 & 31.4 & 1.33 & 26.9 \\
\hline
\end{tabular}


Table 3. Comparison of the $V_{\text {test }} / V_{\text {pred }}$ ratio for the proposed model and EC-2 equations using $f_{c m}, f_{c k}$ and materials safety partial coefficients $\gamma_{c}=1.5$ and $\gamma_{s}=1.15$.

\begin{tabular}{|c|c|c|c|c|c|c|c|c|c|c|c|c|c|c|c|c|c|c|}
\hline \multirow{3}{*}{ Comments } & \multicolumn{9}{|c|}{ Code format proposal (Section 4) } & \multicolumn{9}{|c|}{ EC-2 } \\
\hline & \multicolumn{3}{|c|}{ With $f_{c m}$} & \multicolumn{3}{|c|}{ With $f_{c k}$} & \multicolumn{3}{|c|}{ With $f_{c d}$ and $\gamma_{s}$} & \multicolumn{3}{|c|}{ With $f_{c m}$} & \multicolumn{3}{|c|}{ With $f_{c k}$} & \multicolumn{3}{|c|}{ With $f_{c d}$ and $\gamma_{s}$} \\
\hline & Mean & Cov & $5 \%$ & Mean & $\mathrm{Cov}$ & $5 \%$ & Mean & Cov & $5 \%$ & Mean & Cov & $5 \%$ & Mean & Cov & $5 \%$ & Mean & Cov & $5 \%$ \\
\hline RC beams w/o stirrups & 1.17 & 18.5 & 0.81 & 1.28 & 20.4 & 0.86 & 1.67 & 20.4 & 1.12 & 1.10 & 27.9 & 0.77 & 1.15 & 27.7 & 0.79 & 1.72 & 27.8 & 1.18 \\
\hline $\mathrm{RC}$ beams with stirrups & 1.16 & 14.1 & 0.91 & 1.19 & 14.9 & 0.94 & 1.49 & 17.6 & 1.16 & 1.47 & 26.4 & 0.96 & 1.49 & 26.4 & 0.99 & 1.83 & 27.9 & 1.16 \\
\hline PC beams w/o stirrups & 1.21 & 22.1 & 0.88 & 1.33 & 23.5 & 0.93 & 1.72 & 24.3 & 1.14 & 1.56 & 29.8 & 0.86 & 1.58 & 26.9 & 1.02 & 1.98 & 29.6 & 1.25 \\
\hline PC beams with stirrups & 1.18 & 16.5 & 0.93 & 1.24 & 18.3 & 0.94 & 1.61 & 23.4 & 1.14 & 1.54 & 37.2 & 0.83 & 1.57 & 35.9 & 0.91 & 1.92 & 33.1 & 1.13 \\
\hline
\end{tabular}

